This is a postprint version of the following published document:

Velasco, Diego; Quílez, Cristina; García, Marta; Cañizo, Juan F. del; Jorcano, José L. 3D human skin bioprinting: a view from the bio side, in: Journal of $3 D$ printing in medicine, Vol. 2, No. 3 (2018), pp. 115-127.

DOI: https://doi.org/10.2217/3dp-2018-0008

(C) 2018 Future Medicine Ltd. 


\title{
3D human skin bioprinting: a view from the bio side
}

\author{
Diego Velasco ${ }^{1,4}$, Cristina Quílez ${ }^{1}$ Marta Garcia ${ }^{* 1,2,4}$, Juan F del Cañizo ${ }^{3}$ \& Jose L \\ Jorcano*,1,2 \\ ${ }^{1}$ Department of Bioengineering \& Aerospace Engineering, Universidad Carlos III de Madrid (UC3M), Spain \\ ${ }^{2}$ Department of Basic Research, Division of Epithelial Biomedicine, CIEMAT-CIBERER, Madrid, Spain \\ ${ }^{3}$ Department of Surgery, Universidad Complutense de Madrid, Experimental Medicine \& Surgery, Hospital General Universitario \\ Gregorio Marañón, Madrid, Spain \\ ${ }^{4}$ Department of Basic Research, Instituto de Investigación Sanitaria de la Fundación Jiménez Díaz, Madrid, Spain \\ *Author for correspondence: jjorcano@ing.uc3m.es
}

Based on the 3D printing technologies and the concepts developed in tissue engineering during the last decades, 3D bioprinting is emerging as the most innovative and promising technology for the generation of human tissues and organs. In the case of skin bioprinting, thanks to the research process carried out during the last years, interfollicular skin has been printed with a structural and functional quality that paves the way for clinical and industrial applications. This review analyzes the present achievements and the future improvements that this area must bring about if bioprinted skin is to become widely used. We have made an effort to integrate the technological and the biological/biomedical sides of the subject.

First draft submitted: 27 February 2018; Accepted for publication: 4 July 2018; Published online: TBC

\section{The skin barrier: structure \& functions}

The skin is the largest organ of the body, typically making up 15-20\% of total body weight, with an external surface area of $1.8 \mathrm{~m}^{2}$ in adults. It is our main defense against a variety of environmental assaults such as microorganisms, ultraviolet radiation and toxic or mechanical agents [1-5]. Probably its most important role is to prevent loss of water (dehydration) and other bodily components. The skin also has important immune, sensory and metabolic functions (e.g., it synthesizes vitamin D) and helps to regulate body temperature [6]. Therefore, it plays a very relevant role in body homeostasis. In addition, skin can be the target of several prevalent disorders of different etiology, including inflammatory and autoimmune diseases, cancer, chronic ulcers and wounds.

To perform these varieties of functions, skin is organized in three different layers (see Figure 1A):

- The epidermis is a rather complex stratified epithelium. It is composed primarily of keratinocytes (at least 80\%) but also contains other cells: melanocytes, dendritic cells derived from the neural crest, responsible for the production of the pigment melanin [7]; langerhans cells, dendritic cells derived from the bone marrow, involved in a variety of immune responses; Merkel or tactile epithelial cells, oval-shaped mechanoreceptors in contact with the nerve cells involved in tactile sensitivity. The thickness of the epidermis varies in the range of $0.05-1.5 \mathrm{~mm}$ from the eyelid (the thinnest layer) to the palms and soles of the feet (the thickest layers). The epidermis is commonly divided into four layers (Figure 1C), the basal layer (stratum basale or germinativum), the squamous layer (stratum spinosum), the granular layer (stratum granulosum) and the cornified layer (stratum corneum) $[8,9]$. In the body regions exposed to friction (palms and soles) the stratum corneum is thicker and there is an additional layer, the stratum lucidum. Skin is a dynamic organ in constant regeneration, as cells of the outer layers are continuously lost and replaced by inner cells moving up to the surface; human skin is renewed approximately every month. This is due to a process in which keratinocytes generated at the basal layer - the only epidermal proliferative layer - migrate to the surface while they follow a program, called terminal differentiation resulting in keratinization and cell death which in turn results in the formation of the horny stratum corneum, the actual protective barrier of the skin [8]. In addition to aforementioned 'interfollicular epidermis', the epidermis gives rise to three appendages: nails, hair follicles and associated sebaceous glands and sweat glands. The hairs and the nails protect the organ. Sweat glands are involved in the control of body temperature. Hair follicles are also particularly important for epidermal regeneration (see the section on 'Wound healing').

Future Medicine 




Figure 1. Skin structure. (A) Scheme representing the main structural components of the skin. (B) Histological tinction showing in detail the structure of interfollicular skin. (C) Scheme showing the cell layers present in differentiated epidermis.

Images adapted with permission from Servier Medical Art freeware image bank (Figure 1A \& C) and www.melanoma.blogsome.com and www.mrcophth.com (Figure 1B).

- The dermis is a layer that, contrary to the epidermis, is relatively acellular and is mostly composed of collagen (types I and III) and elastic fibers (elastin). The dermis is thicker on the dorsal side of the body where it is 30 40-times as thick as the overlying epidermis and in the external areas of the extremities [8]. The most abundant cells are the fibroblasts, although it also contains macrophages and adipocytes. Additionally, it accommodates blood vessels, nerves, glands and hair follicles.

The dermis comprises the bulk of the skin and provides its pliability, elasticity and tensile strength. The epidermis and dermis are connected by the basal lamina, a complex structure composed of proteins such as collagen IV and VII and laminins, involved in the attachment of the two skin layers. Mutations in these proteins are the basis for different subtypes of epidermolysis bullosa, a group of inherited severe blistering disease [10,11]. The major constituent of the dermis is type I collagen, although collagen III is found also in the matrix. Both collagens are not organized in a specific manner, but the ratio between the two varies throughout the human life span because of a decrease in the amount of type III with age. Loosely positioned collagen and elastic fibers are found in the papillary dermis, whereas heavy bundles are present in the reticular dermis (Figure 1B). Another relevant molecule in the dermal extracellular matrix (ECM) is hyaluronic acid, which has become very popular in cosmetics in recent years due to its role in skin hydration $[8,12,13]$. In addition, this molecule plays relevant roles in different processes: morphogenesis, wound healing, inflammation and angiogenesis. All these components and structures provide skin with its characteristic mechanical properties and resilience.

- Finally, the hypodermis consists of loose connective tissue that joins skin to subjacent organs and is mainly composed of adipocytes. It varies in thickness depending on the skin site. The subcutaneous tissue constitutes a storehouse of energy and produces leptin, a hormone that regulates body weight by way of the hypothalamus [8].

\section{Wound healing}

In addition to skin's complexity as an organ, we should likewise refer to its anatomical functions. Skin covers the whole body, and contrary to other organs, it is in contact with the external environment. Due to this function, it is subjected to injuries of a different nature and severity, which is why it is programed to repair itself. In addition 
1)

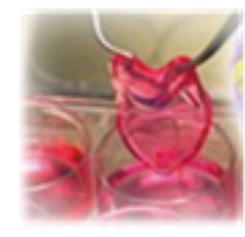

2)

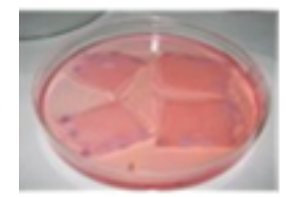

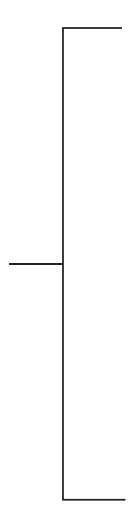

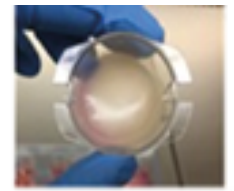

3)

\section{In vitro testing}

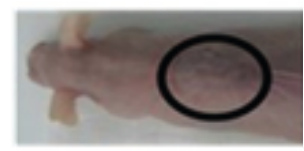

4)

Human disease research: Skin humanized mouse models



Clinical treatment

Figure 2. Main applications of current in vitro, manually produced skin substitutes. (1) Human skin cultured in vitro for experimental use. (2) Human skin mounted on Urgotul ${ }^{\circledR}$ for clinical applications. (3) Human skin differentiated in a transwell for testing purposes. (4) Human skin produced with cells from normal or skin-diseased donors grafted to the back of a nu mouse. (5) Human skin, as in (2), grafted to a wound site.

to this homeostatic mechanism, it is exposed to additional damages. One of the most important mechanisms from a clinical point of view is wound healing; regeneration starts immediately after a wound occurs. The process is regulated by different cytokines and growth factors that activate many intracellular and extracellular processes of different types that lead to the different steps [14,15]. Because of an injury, platelets aggregate and form a plug of fibrin, where immune cells are then attracted. After that, a new tissue matrix is produced by fibroblasts by the generation of collagen III. Finally, re-epithelialization is carried out by keratinocytes, which eventually includes revascularization of the wound [16]. The final phase of wound healing is matrix formation and remodeling. In this phase, that can take several months, there is a slow accumulation of type I collagen bundles and a progressive restoration of the mechanical properties of injured skin to resemble normal tissue architecture. Depending on the depth of the injury, wounds can be classified into four groups: epidermal; superficial partial thickness; deep partial thickness; and full thickness $[17,18]$. If the depth of the injury compromises the hair bulge neither the hair follicle nor its corresponding glands will regenerate. Additionally, re-epithelialization of the epidermis will occur from the edges of the wound and not from the hair follicle, which for an extensive wound will slow down the process or even end up as a chronic wound. This is because this part of a hair follicle contains a reservoir of cells indispensable for these processes to occur $[19,20]$. The wound healing process reveals that both hair follicles and fibrin clots are key in the skin regeneration process.

\section{In vitro engineered human skin substitutes}

There is a huge demand in the development and production of in vitro-engineered substitutes that mimic human skin, either to be used as grafts to restore the function of the skin after damage and to facilitate wound healing or for the establishment of human-based in vitro skin models for toxicity, cosmetic and pharmaceutical testing (Figure 2) [21-27].

To have an idea of the dimension of the problem, we might consider the following figures: First, the WHO estimates that nearly 11 million burn injuries per year worldwide require medical attention, with approximately 265,000 leading to death [28]. Second, the 2016 global wound management market hits $\$ 15$ billion and forecasted to be worth over $\$ 22$ billion in 2024 [29-32]. Third, the tissue-engineered skin substitutes market, which is of particular interest to this review, was valued at 958.8 million US dollars in 2014 and is projected to reach 3873.5 million US dollars by 2023 . To restore the skin after damage and to facilitate wound healing while avoiding immune rejection, autologous grafts (autografts) obtained from the own patients donor areas are commonly used. Unfortunately, the availability of autografts for wound coverage is insufficient when dealing with large and/or severe wounds or burns, hence, the convenience of having in vitro methods of generating autologous skin to apply to these patients [33-35]. 
In the case of in vitro toxicology testing, the market was valued at around 14.2 billion US dollars in 2016 being Europe the largest market with some 6.4 billion dollars followed by North America with 4.8 and Asia with 1 [36]. In the case of skin testing, many drugs can not be tested directly on humans [37]. Therefore, researchers in the pharmaceutical and the cosmetic industries were and are using animals to test their products, with mice being the most common ones utilized. However, testing products on animals is not always predictive of responses in humans and may later lead for instance to costly failures in clinical trials and other economic problems [38]. In addition, testing cosmetic products and their ingredients on animals was banned in the UK in 1998 and across the EU in 2013 (EU Regulation 1223/2009 - Cosmetics Regulation). In this complex situation, it is however predicted that the market will witness a rapid growth thanks to the increasing acceptance of in vitro methods over in vivo ones, the arrival of new and promising technologies, and the advancement in new approaches as the ones discussed in this review.

Thus, as a result of the foregoing, skin substitutes are being explored for human skin replacement therapy and for human skin testing, such as acellular skin substitutes or cellular skin substitutes (containing autologous or allogeneic keratinocytes, fibroblasts and adipocytes) as cellular monolayers (epidermal substitutes), cellular bilayers (dermoepidermal components) and cellular trilayers (dermo-epidermis-hypodermis components) skin substitutes [39-47]. Cellular bilayered skin substitutes must fulfill certain conditions: contain well-formed epidermis and dermis; the dermal component should have mechanical properties similar to the dermis; include well-differentiated epidermis with stratum corneum; dermis and epidermis must be properly linked by the basal layer.

The production of bilayered and trilayered artificial human skin usually involves the use of a scaffold composed of natural and/of synthetic polymers such as alginate, collagen, chitosan, fibrin, hyaluronic acid and poly(ethylene glycol), polycaprolactone (PCL), poly (vinyl alcohol) and polylactic acid and poly-L-lactic acid, respectively [48-52]. Among them, collagen (the main component in the ECM) and fibrin (the blood component) have been used extensively to provide structural and mechanical support [53-56]. This scaffold is usually filled with fibroblasts (dermal component), and keratinocytes are seeded on top of the dermal component. In the case of trilayered skin substitutes, below the dermal component another scaffold is filled with adipocytes or mesenchymal cells.

As an example of production of autologous human artificial skin, our lab engineered a human plasma-derived bilayered skin using primary human fibroblasts (hFBs) and keratinocytes (hKCs) from skin biopsies to treat burns and traumatic and surgical wounds in a large number of patients in Spain and for the generation of skin-humanized mouse models (Figure 2) [57-59]. In this case, skin substitutes formed by two layers, representing the dermis (the lower layer) and the epidermis (the upper layer), were generated following the method developed in [57]. The lower layer was a human plasma-derived fibrin matrix populated with hFBs and the upper layer was formed by hKCs, seeded confluent on the top of the fibrin scaffold (Figure 3). At this point, for clinical use, the equivalents can be transplanted to the patients. After grafting, the layer of epidermal cells, now in contact with the air, proliferate and differentiate to form all the layers of the epidermis, including the stratum corneum. Simultaneously, growth factors and chemo attractants produced by the HKCs and hFBs stimulate the growth of patient's blood vessels and in a very short time invade the transplanted skin. A very similar process occurs, when, for experimental purposes, human skin equivalents are grafted onto the back of immunodeficient mice (skin-humanized mice). For in vitro studies, the terminal differentiation of the epidermis is achieved by placing the culture at the air-liquid surface.

We have devoted an effort to explain the commercial relevance and the estructure, composition and production of human bi/trilayered human skin equivalents, because as we will see in the forthcoming sections, 3D skin bioprinting follows the same principles. In spite of the notorious advanced in this field, several aspects of human skin equivalents need to be addressed. On the one side, they have to include other types of cells and molecules found in normal skin to improve their clinical and dermatological performance. And, on the other side, the complex manual and strictly regulated production lead to elevated prices. These limitations combined with a foreseen higher demand for artificial human skin, have all led to an increasing need to develop new methods that offer automation, standardization and reduction in time to manufacture the bilayered skin substitutes and production costs $[60,61]$.

\section{D bioprinting}

Three-dimensional bioprinting has emerged as a flexible tool in regenerative medicine and provides a platform for addressing some of the needs described above. Three-dimensional bioprinting can be defined as the spatial patterning of cells, cell aggregates, DNA, drugs, growth factors, bioactive substances, extracellular components and biomaterials, referred to as bioinks, by assembling them using a computer-aided layer-by-layer deposition approach for the fabrication of artificial tissues or organs or constructs for drug screening, toxicology studies and clinical 


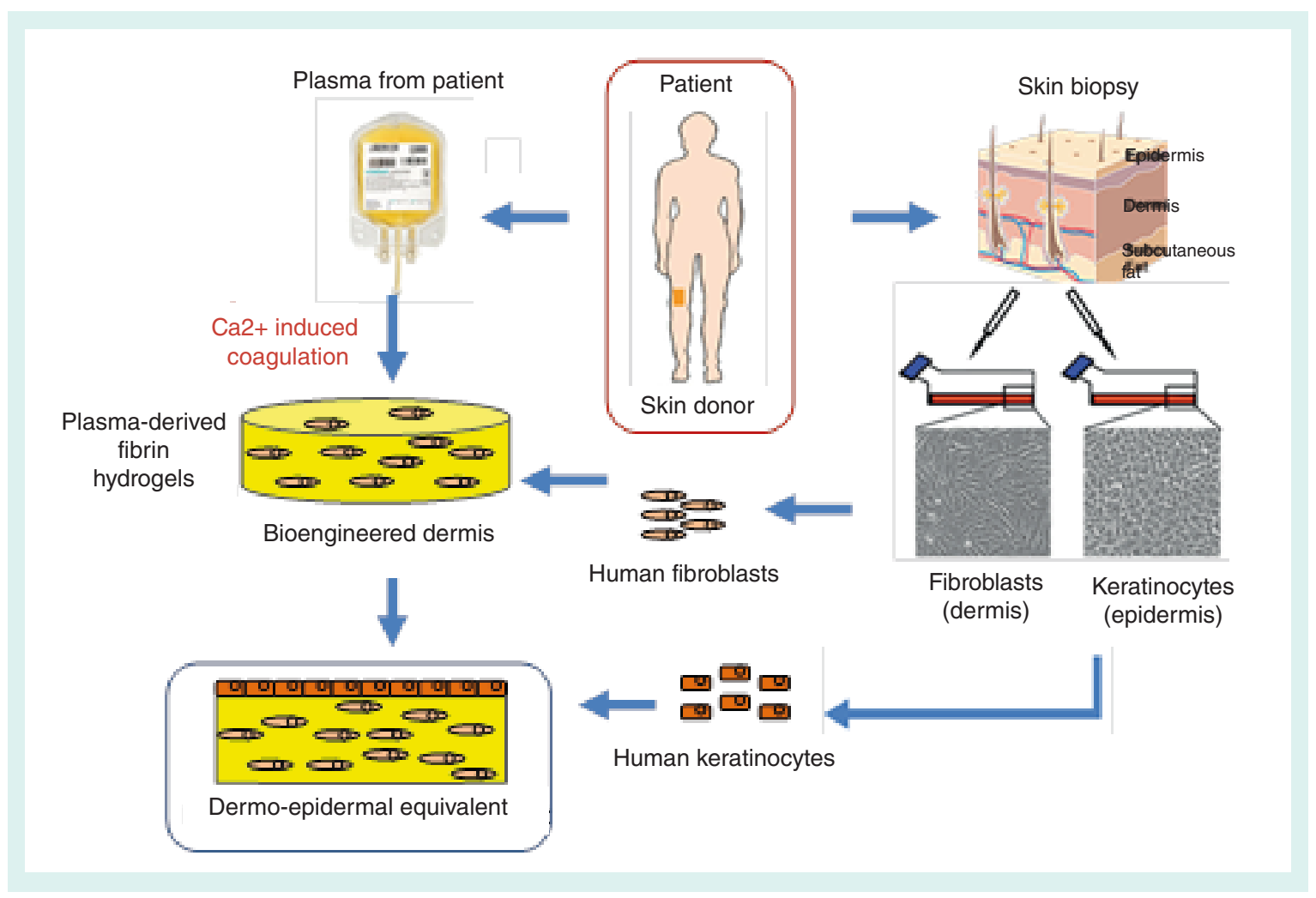

Figure 3. Scheme of the production of large surfaces of autologous skin equivalents from a small biopsy. From a small (2-4 $\left.\mathrm{cm}^{2}\right)$ biopsy, human fibroblasts and primary human keratinocytes are isolated and separately expanded in vitro using cell culture techniques well known in the field [59]. Once obtained the required high number of cells, they are assembled into a multilayered skin equivalent. In a first step, the dermal compartment is generated by adding calcium to human plasma and introducing the primary human fibroblasts cells at the appropriate density while fibrin polymerization is taking place. Once the dermal hydrogel has polymerized, human keratinocytes are seeded on top of it and allowed to grow until confluency. At this moment, they can be removed from the culture plates, properly packed and sent to the hospital for transplantation.

use [62-73]. Although there are several definitions concerning 3D bioprinting, in this review we will consider 3D bioprinting a process that applies $3 \mathrm{D}$ printing principles and technologies to the generation of human tissues using bioinks containing fundamentally cells and the materials needed to generate scaffolds.

Gartner, an American research and advisory company, has become a standard reference in 3D printing benchmarking. Its 2017 3D Printing Hype Cycle provided a comprehensive analysis of the most relevant 3D printing applications and their respective level of maturity [74]. Figure 4 shows the situation in this Hype Cycle of bioprinted biomedical products. Three-dimensional bioprinted organs for transplants and drugs are placed in the innovation trigger phase' (the value is triggered by the expectations raised by the disruptive innovation) with estimations of $>10$ years to reach the market. Three-dimensional bioprinting for life science $\mathrm{R} \& \mathrm{D}$ is placed in the transition between the 'peak of inflated expectations' and the 'through disillusionment' phases (indicating that expectations are entering into a more realistic phase) with estimations of 5-10 years to reach the market. Three-dimensional bioprinted human tissue has advanced to the 'through disillusionment' phase (indicating that difficulties are being identified) with estimations of 5-10 years to reach the market. However, this prediction could be too pessimistic given that in 2016 the first paper claiming to have produced a functional human tissue through 3D bioprinting was published.

Regarding its possible economic impact, we are not aware of any estimation of the market value of bioprinted skin. However, according to Grand View Research, by 2022, the global 3D bioprinting market is expected to reach 1.82 billion US dollars and will include products and materials for dental, medical, analytical and food applications. In North America, this value is around 550 million US dollars, of which around 350 million US dollars correspond to medical applications. On the other hand, as previously presented in section 2, the wound management market 


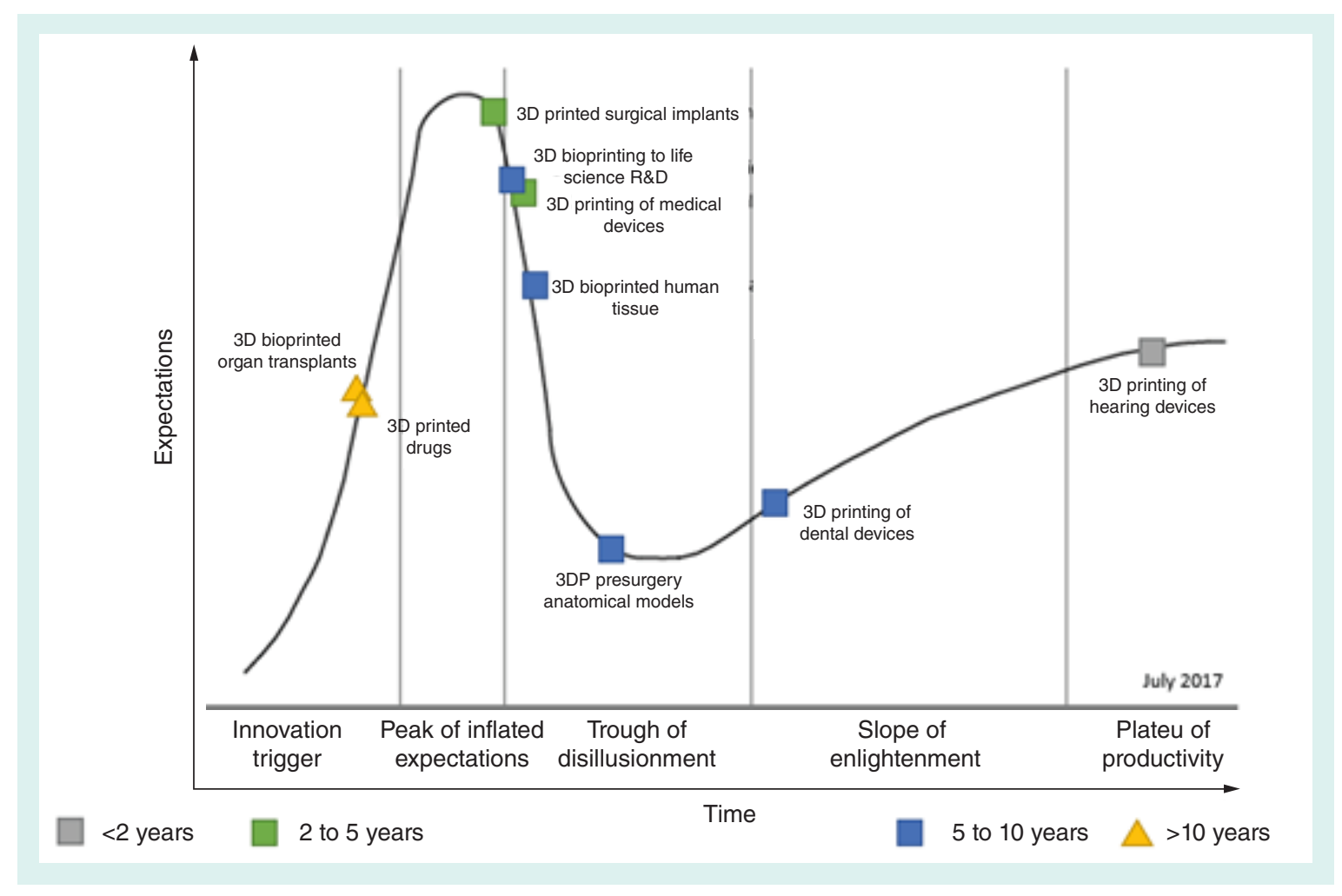

Figure 4. The 2017 3D Printing Hype Cycle provides a comprehensive analysis of the most relevant 3D printing applications and their respective level of maturity. The figure shows selectively the situation in this Hype Cycle of bioprinted biomedical products.

Modified or adapted with permission from [74].

value is expected to be worth over 22 billion US dollars in 2024, the global tissue-engineered skin substitutes market is projected to reach 3873.5 million US dollars by 2023 and the global in vitro toxicology market is expected to be worth 17,227 million US dollars this year. It is clear that 3D bioprinted human skin will play an important role in all these markets either for clinical or testing applications.

\section{Components of a 3D bioprinter}

Three-dimensional bioprinters are printers specifically designed or adapted to work with bioinks containing living cells, biomaterials and biocomponents that are very sensitive to processes such as high temperature, fluid stress, UV light, compression, etc., present in conventional 3D printers. Bioprinters can either be custom made according to user needs or can be acquired to one of the several companies that commercialize them. In this last case, it might have to be adapted to one's specific requisites. Although there are different types of 3D bioprinters (see section 3.2), this section will describe an extrusion-based bioprinter as this type is widely used in research and is a good model to use for explaining the main issues concerning any bioprinter's architecture and functioning.

A bioprinter is comprised of four main components (Figure 5):

- First, a software system which is responsible for the communication between the bioprinter and the computer, and therefore the user. It controls the ejection of the bioinks from the cartridges and the positioning of the dispensers through computer-aided design/computer-aided manufacturing.

- Second, the extrusion module containing the cartridges, the actuators and the dispensers or nozzles. The cartridges act as reservoirs containing as many bioinks as necessary and they can be one or several, depending on the number and characteristics of the bioink and the bioprinting process. The actuators, under the control of the computer and with great precision, pump the amount of each bioink necessary at any moment from the cartridges to the nozzles. There are different methods to carry out this ejection, ranging from using mechanical energy to optical energy (see section 3.2). The dispensers are involved in the extrusion and the deposition of the bioink, and are 


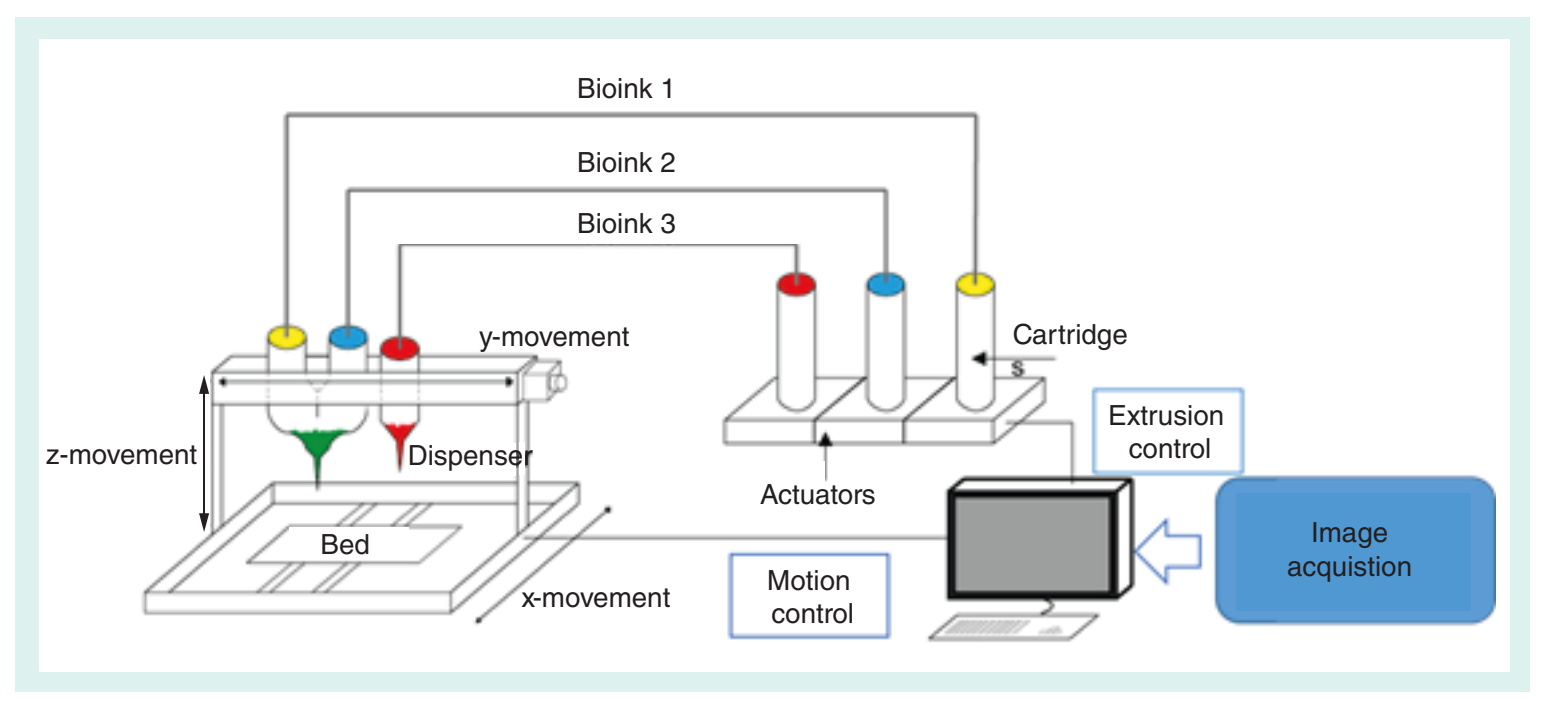

Figure 5. Scheme of an extrusion-based 3D bioprinter.

positioned in the $\mathrm{x}, \mathrm{y}$ and $\mathrm{z}$ coordinates with the help of the positioning system. The shape, and in particular, the diameter of the nozzle is very important because it has to fulfill somewhat contradictory functions: not damage bioink, in particular cell viability, and define the resolution of the deposition. Thicker nozzles will favor bioink viability but decrease precision, and vice versa. On the other hand, tapered needle-type nozzles are known to damage fewer cells and biomaterials than cylindrical needle-type nozzles [75]. The cartridges and the dispenser can be integrated or independent. In this case, they are connected by sterile, flexible tubes with a diameter that can accommodate the liquid flow and not damage the cells and other biological components. Another function of the dispenser is acting as a reservoir in which two or more bioinks are mixed before being dispensed. The number of cartridges and dispensers can vary according to the printing requirements. For instance, the number of cell types and biomaterials, temperature control, etc. Additionally, it is possible to combine different extrusion systems to improve the versatility of the bioprinter.

- Third, the printing module consists of the positioning system and the printing bed (the place generally is a tissue culture plate where the deposition takes place). The bed is on a platform that can be heated, frequently at $37^{\circ} \mathrm{C}$. The printing module must position the nozzle in the space under computer control. For this, the movement of the two module components must be coordinated. For example, if the bed moves in the $\mathrm{x}$ and $\mathrm{y}$ axes, then the dispenser should move in the $\mathrm{z}$ axis; if the dispenser moves in the $\mathrm{x}, \mathrm{y}$ and $\mathrm{z}$ axes, the bed will be fixed.

- Fourth, the bioinks for bioprinting, defined in section 3, fundamentally contain cells and materials needed to generate the scaffolds [76-79]. Cells are particularly important from a biological point of view and are critical as they are sensitive to external conditions. Therefore, cell selection and survival are crucial points to be addressed when establishing the conditions of the bioprinting process (cell handling and density, residence time, buffers, temperature, shear stress, etc.) [80-82]. As an example, in the case of skin bioprinting, it is very important to control the time that keratinocytes are in the cartridge because they are known to differentiate when kept in suspension [83].

Another very important issue to be considered when designing the bioprinting process of a tissue is the selection of the scaffold. This involves taking into account parameters such as biocompatibility, biodegradability, porosity and mechanical properties which are highly dependent on the type of tissue to be printed. For instance, in the case of hard tissues such as bone, they require more rigid scaffolds made of ceramics, PCL, polylactic acid or mixtures among them have been widely used. In the case of soft tissues, hydrogels are the most common scaffolds, given that they can be defined as crosslinked 3D network structures that can absorb and retain large amounts of water and provide a hydrated and highly permeable microenvironment, mimicking the natural ECM in this type of tissues. They can be made of natural components (fibrin, collagen, gelatin, alginate, agarose, hyaluronic acid, etc.) or synthetic (very frequently poly(ethylene glycol) polymers or both [84-86]. There are two parameters that need to be particularly controlled in hydrogel design: rheological properties (especially viscosity) and gelation time. The 


\begin{tabular}{|c|c|c|c|c|}
\hline Base material & Composition & Cell types & Bioprinting technology ${ }^{\dagger}$ & Ref. \\
\hline Collagen & Collagen & $\mathrm{HaCaT}^{1}, \mathrm{hFB}^{2}, \mathrm{hKC}^{3}$ & Droplet based & {$[115,116]$} \\
\hline Human plasma & Human plasma and alginate & $\mathrm{NIH}-3 \mathrm{~T}^{4}, \mathrm{HaCaT}^{1}$ & Laser based & [126] \\
\hline Fibrinogen & $\begin{array}{l}\text { Fibrinogen, alginate and } \\
\text { gelatin }\end{array}$ & $\mathrm{hKC}^{3}, \mathrm{hFB}^{2}$ & Extrusion based & [93] \\
\hline Collagen & Collagen and fibrinogen & $\begin{array}{l}\mathrm{hKC}^{3}, \mathrm{hFB}^{2}, \mathrm{HaCaT}^{1}, \mathrm{AFSC}^{5}, \\
\mathrm{MSC}^{6}\end{array}$ & Droplet based (in situ) & [132-135] \\
\hline Collagen & Collagen & $\mathrm{hFB}^{2}, \mathrm{hKC}^{3}, \mathrm{hMC}^{7}$ & Droplet based & [128] \\
\hline Collagen & Collagen and fibrinogen & $\mathrm{hKC}^{3}, \mathrm{hFB}^{2}, \mathrm{HMVEC}^{8}$ & Droplet based & [129] \\
\hline
\end{tabular}

${ }^{\dagger}$ Ex vivo bioprinting, if not otherwise stated.

$\mathrm{AFSC}^{5}$ : Amniotic fluid-derived stem cell; $\mathrm{HaCaT}^{1}:$ Immortalized human keratinocyte; $\mathrm{hFB}^{2}$ : Primary human fibroblast; $\mathrm{hKC}^{3}$ : Primary human keratinocyte; $\mathrm{hMC}^{7}$ : Primary human melanocyte; $\mathrm{HMVEC}^{8}$ : Human dermal microvascular endothelial cell; $\mathrm{MSC}^{6}$ : Bone marrow-derived mesenchymal stem cell; $\mathrm{NIH}_{-3} \mathrm{~T}^{4}$ : Immortal murine fibroblast.

viscosity has to be carefully balanced. On the one hand, highly viscous bioinks will need high pressure to flow through the nozzle which might bring about cell damage and/or require wider nozzles leading to a lower precision. This problem is particularly relevant in the case of droplet-based bioprinting and not so much in extrusion-based bioprinting (EBB; bioprinting technologies will be discussed in section 3.2). On the other hand, low viscosity bioinks will tend to spread out on the receiving bed. This is particularly relevant in the case of printing structures with a defined 3D pattern but not so much in the case where the printing is performed in a confined container, a very common situation in soft tissues bioprinting. An efficient manner of providing viscosity at the moment of the deposition is the use of sacrificial materials. The bioink should undergo a gelation process. If it is too rapid, it might provoke clogging inside the nozzle, but if it is too slow it will prevent maintaining the shape and the spatial pattern initially printed in those cases where high resolution is required. An efficient manner recently described to overcome this problem is the inclusion of sacrificial material in the bioinks. These materials provide initial viscosity and are washed out once the hydrogel polymerization is completed. Examples of materials used to this end are gelatin, pluronics, etc. [87,88]. These sacrificial materials clearly provide more flexibility when designing the bioprinting process because they allow the printing complex structures using scaffolds that themselves would not allow it. Because of the complex physical and functional properties necessary for scaffolds, their design is a very active area of research, and an increasing number of materials and hybrid natural/synthetic scaffolds are being investigated $($ see $[79,89,90])$ for recent reviews. Among them, only a few have been used as bioinks for the generation of scaffolds in skin bioprinting (Table 1).

The most commonly used are biological polymers, namely collagen and fibrin, the latter obtained either from commercial fibrinogen or from the polymerization of human blood plasma. Collagen is the main molecular component of normal skin dermis while fibrin constitutes the blood clot from which the process of wound healing starts. With the existing results, it cannot be concluded which one leads to better outcomes although, the fibrin hydrogels do not show the contraction that collagen matrices present [91,92]. Given the bilayered structure of skin, the use of sacrificial materials has not been so far necessary in skin bioprinting, with the exception of the work published by Pourchet et al. [93], in which the authors carried out the bioprinting without any physical confinement, so they needed very viscous bioinks to maintain the spatial disposition with which they were deposited.

The printing modality is made based on biological needs: the necessary cells, biomaterials used and their corresponding mechanical and chemical limitations when handling them, and the structure and characteristic of the tissue to be constructed. In 3D bioprinting, three main methods can be distinguished: extrusion-, droplet- and laser-based bioprinting (Figure 6); they can be home-made printers or commercially available ones [94]. 


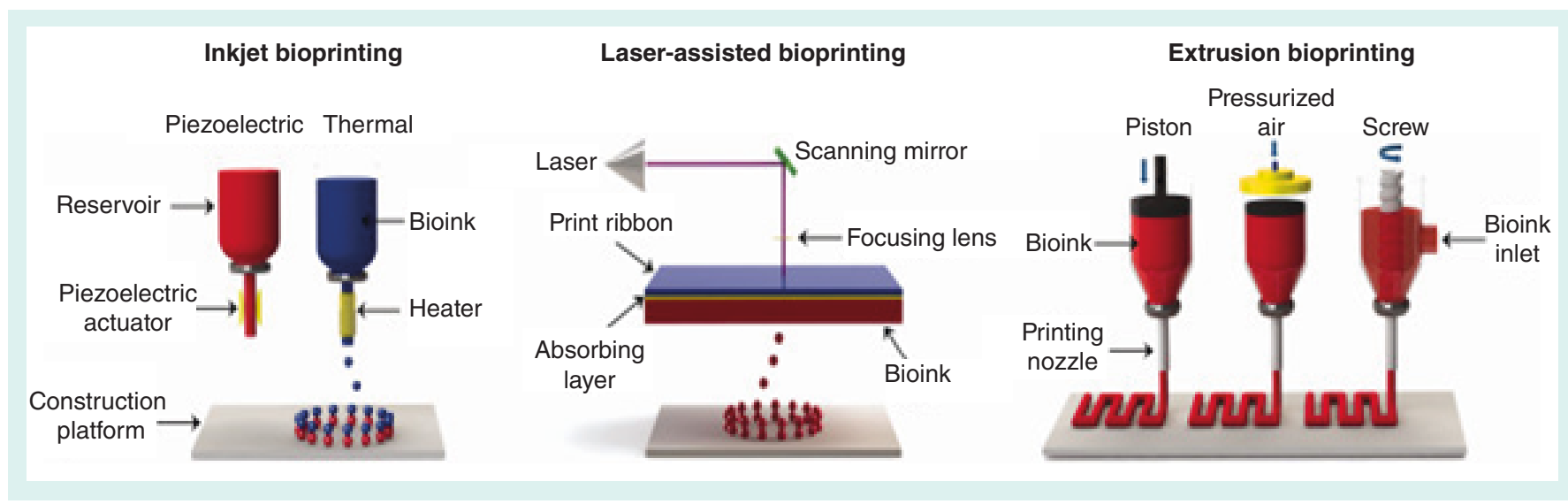

Figure 6. Bioprinting methods. Three main methods are currently used in 3D bioprinting: extrusion-based (extrusion bioprinting), droplet-based (inkjet bioprinting) and laser-based (laser-assisted bioprinting) bioprinting.

Reproduced with permission from [95]. For more details, see the text.

\section{D bioprinting technologies}

Currently three main methods are used in 3D bioprinting: extrusion-, droplet- and laser-based bioprinting. The selection of the method will depend on the properties of the cells and biomaterials used, the precision and speed required, and the size and characteristics of the tissue to be printed.

\section{Extrusion-based bioprinting}

The EBB is the most common modality used in bioprinting research due to its practicality and ability to fabricate larger scale $3 \mathrm{D}$ constructs $[96,97]$. In EBB, the bioink solution is extruded through the dispenser by a pneumatic-, mechanical- (piston or screw-driven) or solenoid-based system in form of a continuous filament.

Some of the advantages are that it has a high printing speed which can facilitate scalability and, additionally, enable the use of a broad range of bioinks in particular cell-laden hydrogels widely used in soft tissue printing [84,98106]. Moreover, the technology is easy to implement, user friendly and affordable. The main disadvantages are less accuracy and lower resolution $(\geq 100 \mu \mathrm{m})$ than other techniques [107].

To our knowledge, this modality is the most used at present in skin 3D bioprinting either alone or in combination with droplet-based bioprinting [93,108,109].

\section{Droplet-based bioprinting}

Droplet-based bioprinting has its roots in inkjet technology (Elmqvist of Siemens, 1950 which evolved into the first inkjet 3D printer (Objet Geometries, 2000) [110]. It relies on the same principle of EBB: there is a continuous extrusion of bioink through a dispenser, but in this case, the continuous flow is interrupted by different actuators to form drops. These drops are then deposited on the printing bed [111].

Droplet bioprinting techniques can be classified depending on the actuator (Figure 6.). The most used modalities are inkjet based and can be classified into piezoelectric, thermal or electrostatic according to the type of actuator used (piezoelectric, thermal or electrostatic) [112-114]. The most important advantages of this type of impression are: first, better resolution; drop diameters as small as 40 um have been reported in bioprinting processes although cell viability can be affected by drop size. Second, complex geometries can easily be patterned. Third, affordable price. Fourth, possibility of constructing hybrid printers with droplet-based+ EBB, which increases the flexibility of the process. The main disadvantages are: first, narrow range of viscosities (3.5-12 mega pascal-second (mPa.s) vs 30-6 $\times 10^{7} \mathrm{mPa}$.s in the case of EBB) which limits bioink composition. Seond, a longer time of impression as compared with EBB, which limits the size of the printed tissue. Third, the method used by the actuator to form the drops, in particular, the thermal modality, can affect cell viability.

This technology has been used in different studies in the generation of 3D-bioprinted skin [115,116], which will be analyzed in more detail later. 


\section{Laser-based bioprinting}

Laser-assisted cell printing is a nozzle-free technique. This technology is based on conventional laser-induced forward transfer. They are two stacked slides mostly made of quartz: first, the donor slide. The lower side of this slide is covered with a laser-absorbing layer plus a layer of bioink, containing the biomaterials and cells to be transferred. Second, the collector slide, equivalent to the printing bed, placed at variable distances ranging from millimeters to micrometers. A high-powered infrared laser pulse is focused onto a small area of the laser absorbing layer of the donor slide, generating a high-pressure bubble that catapults the underlying bioink area onto the collector slide $[117,118]$. To improve printing speed, several lasers can be used to scan the donor slide. There are several variations of this method, mainly based on the composition and characteristics of the donor slide [119,120]. The main advantages of this method are its high precision and that it is smaller than the size of one cell. At present, its main disadvantages are: its expense; it is only suitable for printing small tissue surfaces; the complex fabrication of the donor slide; lower viscosities (1-300 mega pascal-second [mPa.s]) than EBB [121,122]. These drawbacks probably make this technology not the most appropriate for printing interfollicular skin but, as a proof of concept, it was used by the group [123].

\section{D skin bioprinting}

Due to the relatively simple structure of interfollicular skin as compared with other 3D solid organs such as heart, kidney, etc. and its demand in clinical and commercial testing uses, production of skin tissue containing dermal and epidermal components by bioprinting is currently an important area for laboratory research and company development. Although there are three recently published reviews on this topic [18,95,124], we focus instead on aspects that, in our opinion, affect the structure, function and use of bioprinted human skin.

In our opinion, 3D bioprinting would be the method of choice for large-scale skin production for toxicity, cosmetic and pharmaceutical testing. This is due to the fact that it would allow a robust, standardized and automatized method as well as significantly reduced production costs. For this testing purpose, one can previously generate large cell banks established from biopsies obtained from donors. One can even consider the possibility of using immortalized human cells given rise to culture that is close enough to human skin to overcome the regulatory requirements (Lynn-Hoffman [125]). The use of bioprinted skin for testing purposes could reach the market in the near future.

On the other hand, the 3D bioprinting technology would not be able to reduce the time (3-4 weeks) currently needed to obtain enough autologous cells to print large skin surfaces for the treatment of large wounds (e.g., people with extensive burns) from small biopsies. This prolonged amplification step under very costly good manufacturing practices conditions is one of the main factors limiting the usefulness of skin equivalents in wound healing treatment. Therefore, the advantages of 3D bioprinting are limited in this field.

There are two main strategies concerning how to print skin for wound treatment: ex vivo and in situ bioprinting.

\section{Ex vivo skin bioprinting}

In this approach, a skin construct (usually including dermis and epidermis) is printed and, if required, matured (e.g., differentiated) in vitro, and then analyzed in vitro or upon grafting to a patient or an experimental animal. We will discuss the main articles published, classified according to the bioprinting method used. From the chronological point of view, this was the first approach.

\section{Droplet based}

From a chronological point of view, this was the first technology used to print skin. In their pioneering work, Lee $e t$ al. (2009) demonstrated the feasibility of the multilayered deposition of fibroblasts and keratinocytes in a collagen scaffold [115]. Posteriorly, Lee et al. (2014) after optimization of the printing parameters to likewise optimize cell density and viability, generated dermo-epidermal constructs that were exposed to the air-liquid interface to promote the in vitro maturation and terminal differentiation and stratification of the epidermal cells [116]. These authors deposited interspersed layers containing either collagen or collagen-containing hFBs in the dermal compartment or hKCs in the epidermal compartment (Figure 7). In spite of its pioneering value, this alternating deposition of cellular and acellular is unnecessary and does not resemble the skin structure. Apart from that, the main drawback of this method is that the histology of the skin tissue does not show proper stratification and terminal differentiation as compared with human skin. As the authors recognize, this can be, at least in part, due to the use of an immortalized keratinocyte cell line ( $\mathrm{HaCaT}$ cells) instead of primary hKCs. Finally, based on the data provided by the authors, 
(A)

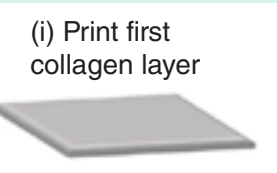

(iii) Print one layer of FBs

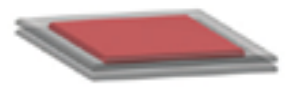

(v) Print two layers of collagen



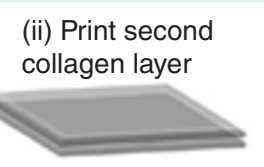

(iv) Repeat steps i-iii three times

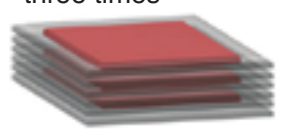

(iii) Print two layers of KCs

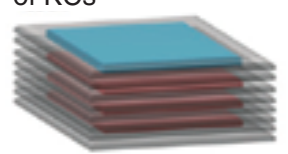

(B)

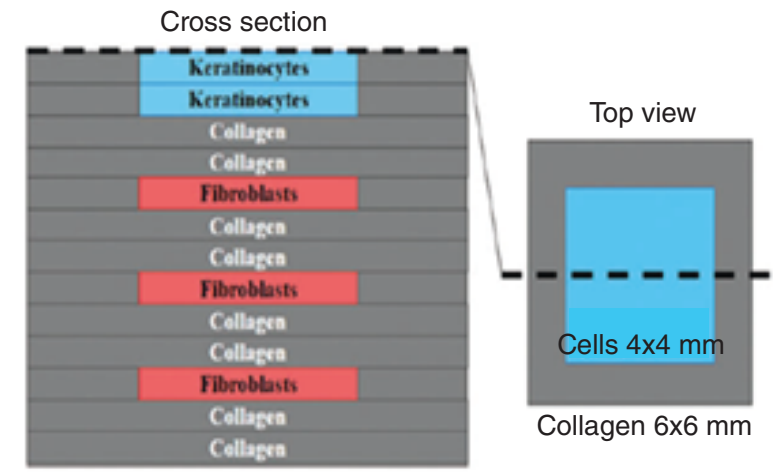

Figure 7. Construction of 3D skin tissue using the microvalve bioprinting system with pneumatic pressure droplet-based technology. (A) Layer-by-layer printing of the collagen matrix, human keratinocytes and human fibroblasts to generate the dermal and epidermal compartments integrated in a single structure. (B) Schematic of the 3D-printed skin tissue showing the cross section (left) and the top view (right).

Modified with permission from [116].

the estimated printing speed allows the deposition of $1 \mathrm{~cm}^{2}$ skin per hour, which is a very slow process considering the sizes needed for clinical or commercial applications.

\section{Laser based}

In this approach, a laser-assisted bioprinting technology was used to deposit alternating layers, containing immortal murine fibroblasts and immortal hKCs (NIH-3T3 and $\mathrm{HaCaT}$ cell lines, respectively) embedded in a collagen matrix (Figure 8) [126]. In this technique, 20 collagen sublayers containing fibroblasts were printed onto a sheet of Matriderm ${ }^{\circledR}[127]$ and subsequently 20 collagen sublayers containing keratinocytes were printed on top of it. The printed equivalents are analyzed either upon in vitro differentiation at the air-liquid interface or upon grafting to the back of nude mice using the dorsal skin full chamber method [123]. A clear problem of this work is again the use of immortalized keratinocyte and fibroblast cell lines, in particular the NIH-3T3 murine fibroblasts that are very different from hFBs. Moreover, the histological and immunohistochemical data presented by the authors indicated relevant differences when comparing their transplanted skin with normal human skin. Most likely, these differences are not attributable to the printing method but instead to the dorsal skin full chamber method that imposes a too short time to obtain a fully differentiated epidermis. Finally, although it is difficult to make an accurate estimation from the data provided by the authors, a caveat concerning this technology is the time it would take to print and the effort that would be required to produce the donor slide to generate skin surface of clinical or commercial interest $\left(50-100 \mathrm{~cm}^{2}\right)$.

In conclusion, the cited articles present several drawbacks: first, in general, they do not use human primary fibroblasts and keratinocytes, simultaneously. The cells used might be less sensitive to the stresses of the bioprinting process, and their proliferation and differentiation characteristics are far different from those of the cells contained in human native skin. Second, the printed layered structures are not reminiscent of normal skin and the skin constructs produced did not possess the structural quality of normal human skin. Probably due to these reasons, since 2015, primary human cells have been used. Moreover, additional cell types such as human endothelial cells and melanocytes have been introduced into the printed skin to make it more similar to normal human skin [128-130].

\section{Extrusion based}

From a practical point of view, this method is simpler and quicker than the two methods described above since, instead of printing a high number of cellular and acellular layers to form the dermis and epidermis, it deposits 


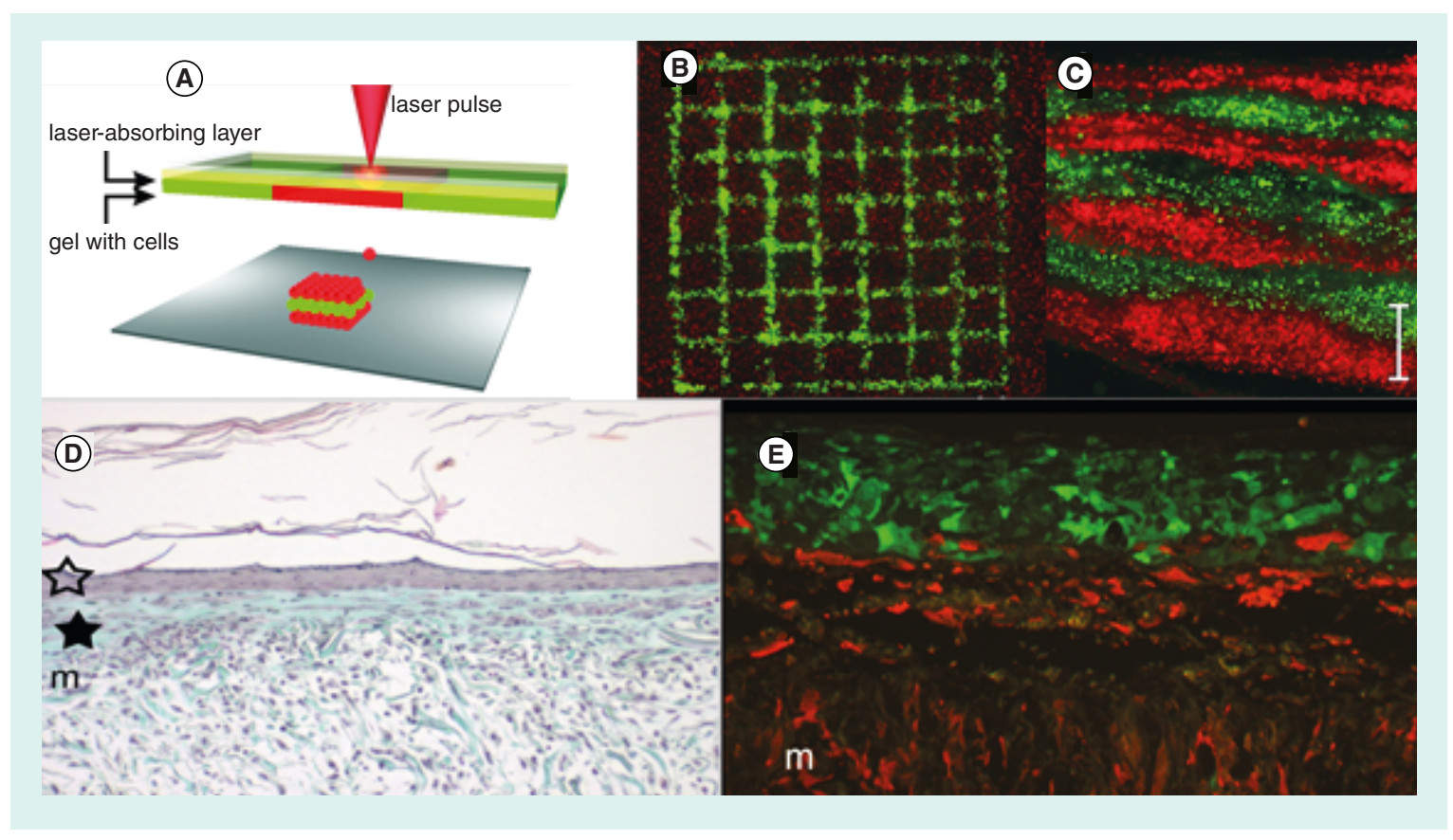

Figure 8. Construction of three-dimensional (3D) skin tissue using laser assisted bioprinting. (A): Sketch of the laser-based printing setup. The cell-containing hydrogel is propelled forward as a jet from the donor slide by the pressure of a vapor-induced bubble generated by the energy transferred by the laser beam to the absorbing layer. Layer-by-layer, a 3D cell pattern is generated. (B) A printed grid structure (top view) of fibroblasts (green) and keratinocytes (red) demonstrates the micropatterning capabilities of the laser-based printing technique. (C) Seven alternating color layers of red and green keratinocytes. Each color layer consists of four printed sublayers. (D \& E) Bilayered skin substitute produced by B laser-assisted bioprinting through the printing of fibroblasts and

keratinocytes, characterized 11 days post implantation in nude mice. (D) Histological section of the bilayered skin substitute stained with Masson's trichrome showing a dense epidermis (empty asterisks) and a corneal layer. The fibroblasts, which stayed on top of the Matriderm ${ }^{\circledR}$, displayed an outstretched morphology being accompanied by collagen deposition (filled asterisks). (E) Fluorescence microscopy image of the bilayered skin substitute with green fluorescence emitted by HaCaT-eGFP cells and red fluorescence emitted by fibroblasts (NIH3T3-mCherry).

Modified with permission from $[123,126]$.

simultaneously all the elements ( $\mathrm{hFBs}$, human plasma and $\mathrm{CaCl}_{2}$ ) required to form the dermis and, on top of this, the hKCs required to form a confluent layer of epidermal cells.

Pourchet $e$ a al. reported a bioink containing bovine gelatine $(10 \% \mathrm{w} / \mathrm{v})$, alginate $(0.5 \% \mathrm{w} / \mathrm{v})$ fibrinogen $(2 \%$ $\mathrm{w} / \mathrm{v}$ ), and primary $\mathrm{hFBs}$ to produce the dermal compartment. The gelatin is used as a sacrificial, rheological material [93]. It provides the printed bioink with temporal mechanical stability and viscosity while alginate and fibrinogen become polymerized in the presence of calcium chloride and thrombin. The bioprinting process takes place at low temperature $\left(28^{\circ} \mathrm{C}\right)$ and the deposition occurs on cool bed $\left(4^{\circ} \mathrm{C}\right)$ temperatures at which gelatin is in a solid phase. The printed dermal equivalent is submerged in a bath containing $\mathrm{CaCl}_{2}$ and thrombin to promote the polymerization of alginate and fibrinogen, and the temperature is then raised to $37^{\circ} \mathrm{C}$ to eliminate the gelatin. Due to the high concentration of the components, the authors have to carefully study the rheological parameters (nozzle length and diameter, viscosity, shear, etc.) to assure the fibroblasts viability. After a 12-day period of submerged culture, keratinocytes are printed on top of the dermal compartment and differentiated at the air-liquid interface. The authors performed an extensive characterization of printed skin by histological, immunohistochemical and electron microscopy methods and concluded that the structure of the printed skin is similar to normal skin (Figure 9). Unfortunately, these authors do not report any in vivo studies such as grafting to the back of nude mice to further evaluate the behavior of this bioprinted skin from a preclinical point of view. The use of high viscosity bioinks containing sacrificial components opens the possibility to bioprinting skin without confinement (for other tissues, see for instance [88]). However, this bioprinting method is more complex and includes a long period of maturation. The decision to use it, thus, has to be carefully balanced given that the confinement-free printing is 
(A)

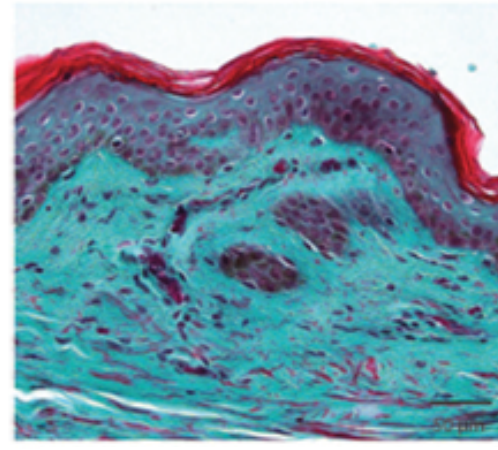

Human skin
(B)

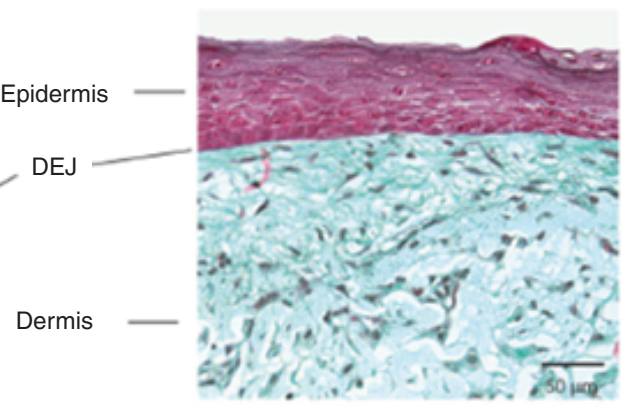

3D bioprinted skin

(C)

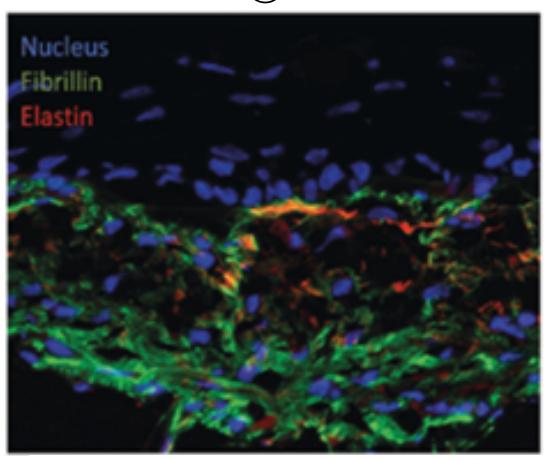

Figure 9. Skin bioprinting using the scaffold-free approach. (A \& B) Histological and morphological characterization of the bioprinted skin using scaffold-free approach. (A) Normal human skin. (B) Bioprinted skin after 26 days in culture. Tissues were stained with Masson's trichrome. (C) Fluorescence microscopy of dermal markers (fibrillin and elastin were abundantly expressed) in the bioprinted skin.

Modified with permission from [93].

not strictly necessary for most clinical and drug-testing skin applications. Bioinks of these types might be of interest for the $3 \mathrm{D}$ future printing of complex tissues and organs.

Based on our previous extensive experience in the manual production of large human skin surfaces and their use in the treatment of extensive burns, skin genetic diseases (epidermolysis) and other types of surgical and loss of substance wounds, as well as in the generation of humanized mice models of human cutaneous diseases, our laboratories have developed a complete system (printer and bioinks) to print human skin for clinical and commercial testing purposes [109]. The initial bioprinter was a very simple, open source device, which we have been constantly modifying and improving. As described in section 2 the dermal compartment is based on a fibrin hydrogel obtained by adding $\mathrm{CaCl}_{2}$ to human plasma (obtained from blood banks) and human primary fibroblasts. The epidermal compartment contains human primary keratinocytes. Both cell types are isolated from biopsies collected from patients or donors.

Our bioprinter contains four different sterile plastic syringes that are pumped by high precision stepper motors to release the required amount of each bioink at each time. The extrusion module contained four syringes, loaded with hFBs (a), plasma (b), CaCl2 (c) and hKCs (d), respectively (Figure 10). The contents of the syringes (a)-(c) were continuously pumped out at the appropriate speed, mixed as they arrived at the head, extruded through the needle and deposited on the corresponding plate type (P100 or transwell), following the trajectories dictated by the control unit. This mixture was allowed to polymerize for $30 \mathrm{~min}$ at $37^{\circ} \mathrm{C}$ to form a fibroblast-containing fibrin hydrogel, which became the dermal compartment of the skin equivalent. Immediately after this polymerization 


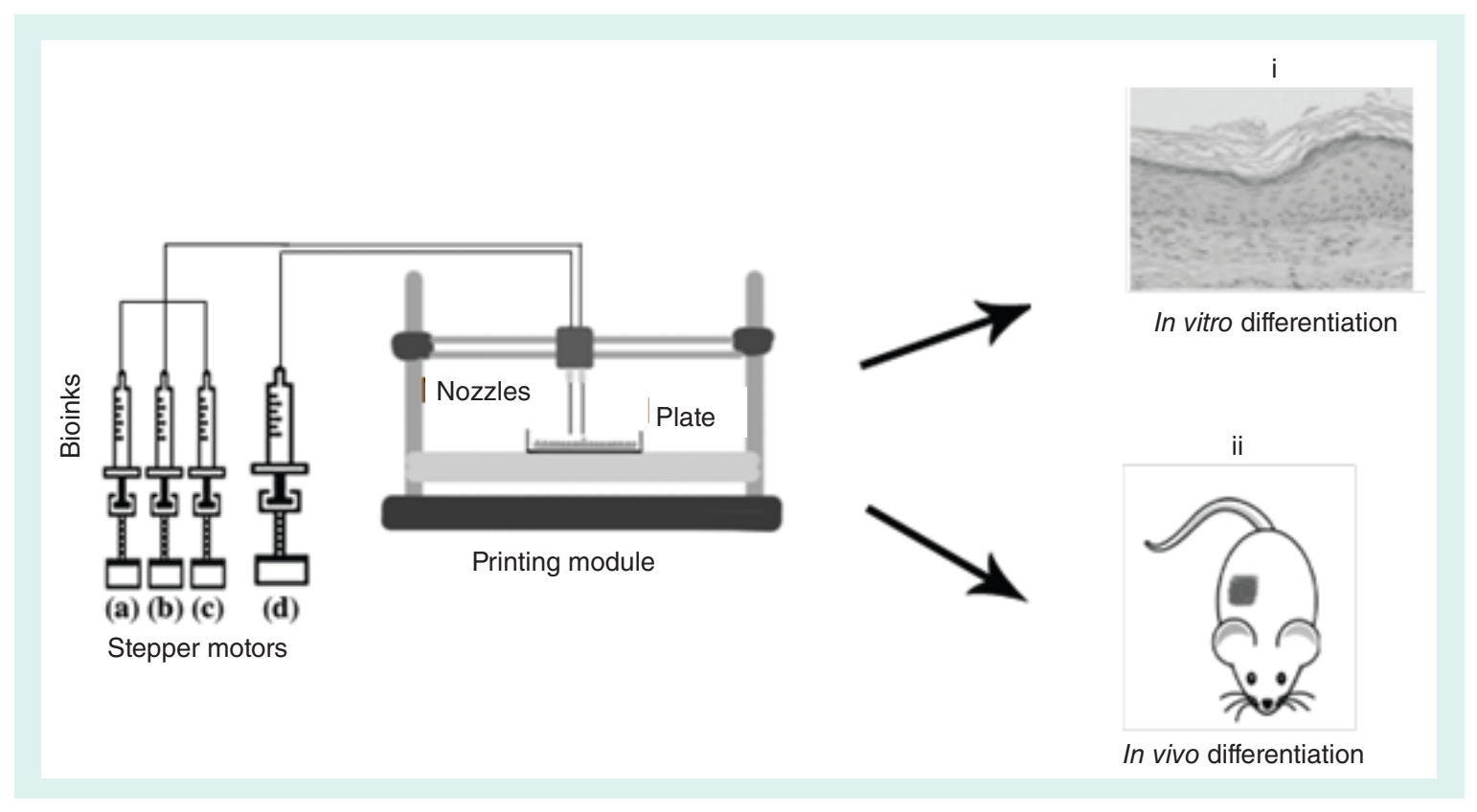

Figure 10. Bioprinting process. See the text for details.

step, the hKCs suspension contained in syringe (d) was similarly deposited on top of this hydrogel to form a confluent monolayer. First, equivalents printed on transwell inserts were allowed to differentiate at the air-liquid surface for 17 days and then analyzed. Second, equivalents printed on P100 plates were grafted on to the backs of immunodeficient mice for 8 weeks and then analyzed.

Depending on the experimental purpose, two different approaches are followed. For in vitro use, the printing process is performed on commercial plastic inserts. The differentiation of the epidermis is induced by placing the cultures at the air-liquid interface for 17 days. For in vivo analysis, printing is carried out on culture plates and the printed equivalents are transplanted to the back of nude mice and are analyzed 6-8 weeks after grafting. In both cases, we have performed a very careful histological and immunohistochemical analysis of the obtained tissue and compared it with hand-made and normal human skin. This analysis demonstrated the presence of well-differentiated skin as shown by the presence of a well-developed stratum corneum and of a basal layer, a critical structure involved in the dermo-epidermal junction (Figure 11). As in the case of [123], blood vessels attracted from the recipient mouse wound bed were detected in the dermis. We also found a formation of rite ridges, a hallmark of mature human skin, to our knowledge never before reported in 3D developed human skin either in vitro or in vivo upon grafting. These encouraging results with interfollicular skin have prompted us to print a more complex construct containing ECM molecules as well as additional cell types and structures to improve the mechanical and functional properties of the printed dermis and epidermis.

Extrusion + droplet-based hybrid methods

Flexibility to attend diverse necessities is one of the hallmarks of 3D printing. In this regard, Kim et al. printed a functional transwell system and human skin in the same process combining extrusion and inkjet bioprinting [108]. The bioprinter, called integrated composite tissue/organ building system (ICBS) system, was formed by six controllable heads, which manage nine bioinks components. The process starts with the printing of the transwell system using the extrusion module. Layer-by-layer deposition of PCL together with gelatin that acts as a sacrificial material will generate the transwell structure (Figure 12). Then, with the use of the same module, collagen I and human primary fibroblast are extruded to form the dermis. After gelation, human epidermal keratinocytes are deposited with high spatial resolution of the top of the gel using inkjet-based module. The construct is submerged in growth media at $37^{\circ} \mathrm{C}$ to reach cell confluency and remove the sacrificial material. Finally, epidermal differentiation is induced at the liquid-air interface in the presence of differentiation medium. This methodology adds the novelty of the in situ fabrication of a transwell system before the printing process of the skin, avoiding the 

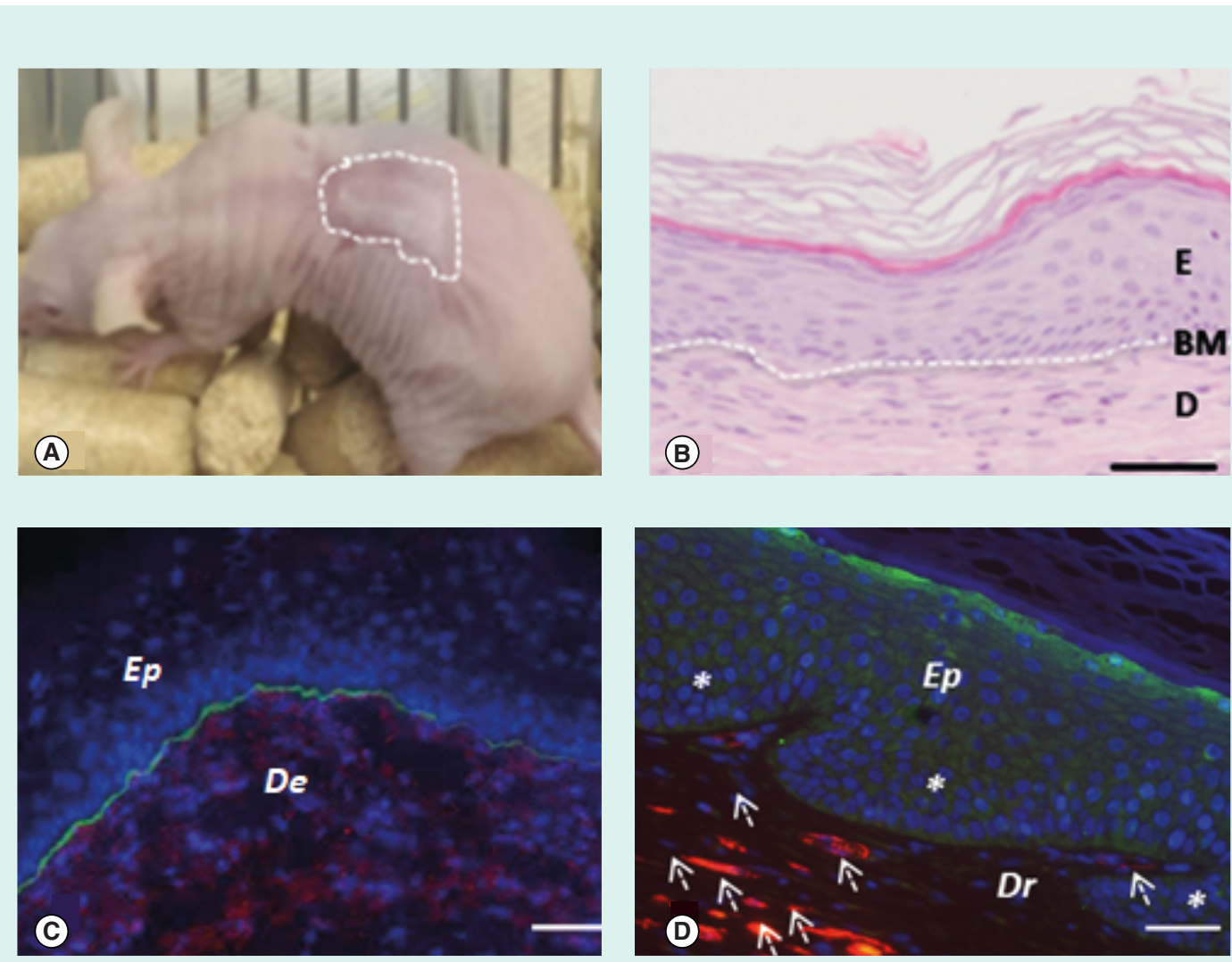

Figure 11. Characterization of a 3D bioprinted skin transplanted to immunodeficient mice. (A) Visual appearance of the grafted human skin. The dotted line marks the boundary between human and mouse skin. (B) Histological analysis ( 8 weeks postgrafting) of bioprinted human skin grafted to immunodeficient mice. The white dotted line in (B) indicates the dermo-epidermal junction (basal membrane). Immunohistochemical analysis (8 weeks postgrafting) of bioprinted human skin grafted to immunodeficient mice using antibodies against skin markers: (C) Antihuman collagen VII (green line between dermis and epidermis) and antihuman vimentin (the red colour in the dermal compartment) detection. (D) Antihuman filaggrin (green staining in the stratum granulosum) and smooth muscle actin (SMA) (red staining) detection. Arrows point to some of the capillaries present in the dermal compartment. Asterisks mark rete ridges. Nuclei were stained with DAPI (blue). For more skin differentiation markers see [109].

use of commercial inserts with a 50-times reduction in cost and with 10-times less medium used, as estimated by the authors. In addition, it prevents the contraction of the collagen matrix which is a chief practical concern found in this extensively used type of scaffolds. The authors justify the need for inkjet-based to obtain a high resolution positioning keratinocytes. They claim that cell distribution and proliferation are improved when compared with manual deposition. It may have been more interesting to compare inkjet versus EBB deposition. An interesting result, presented in the supplementary material, is the illustration that in the EBB method the extrusion conditions and in particular the nozzle diameters that are smaller than approximately 100 um can affect cell viability under the printing conditions used. Finally, as the authors themselves recognized, the histological and immunohistochemical analysis show improper epidermal differentiation and lack of stratum corneum. This is not necessarily an intrinsic drawback of the method, but it could be due either to the experimental conditions used, for instance, a too short time (10 days) at the air-liquid interface or to the stress imposed to the keratinocytes upon droplet formation (the diameter of the dispenser is not explicited).

\section{In situ skin bioprinting}

The concept in situ bioprinting describes a novel mobile skin bioprinting system that includes a hand-held 3D scanner to determine the size and topography of the wound [131]. Contrary to methods described until now that print an ex vivo skin construct which is then transplanted to the wound site of the patient, this in situ bioprinting system 


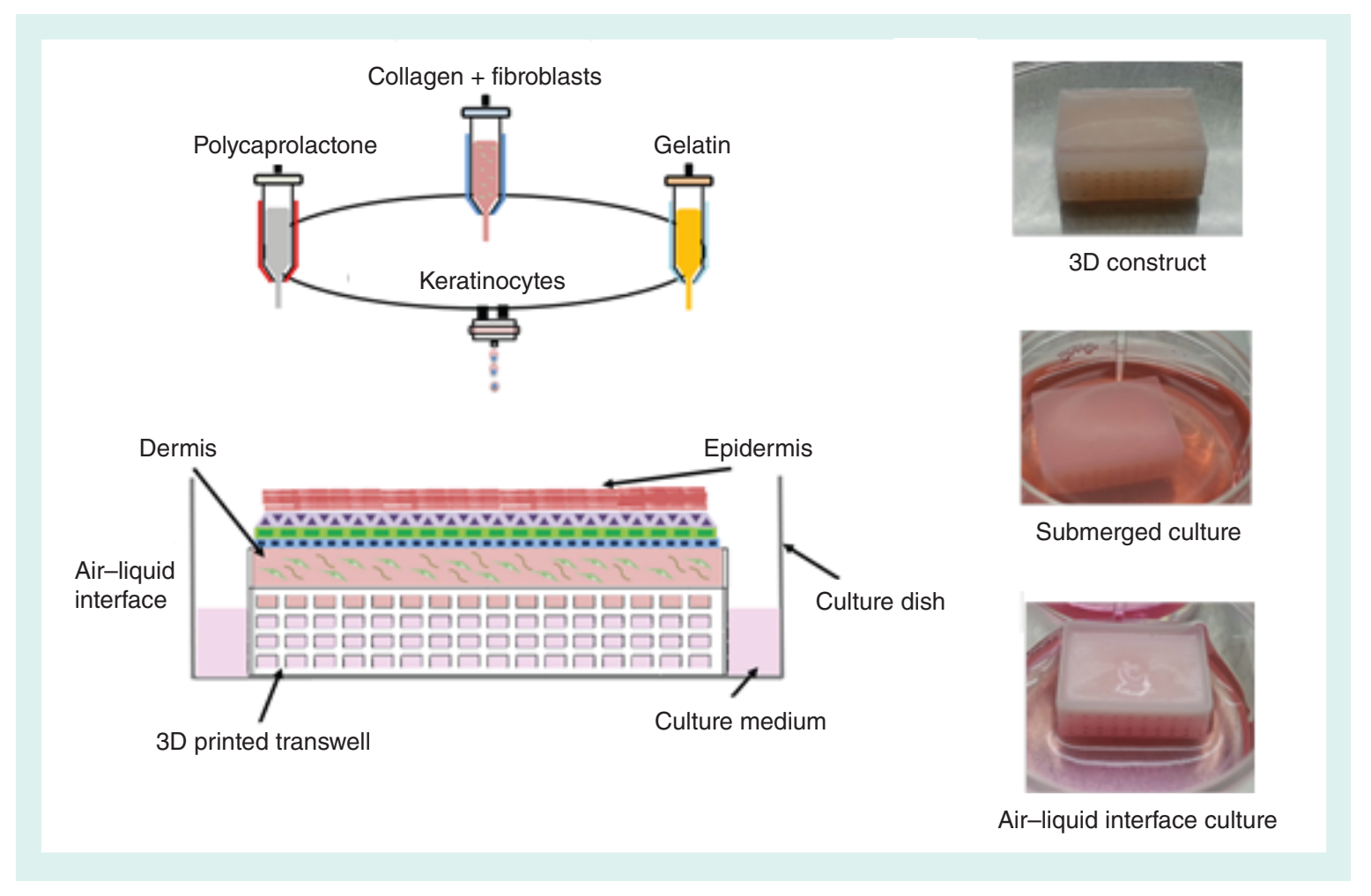

Figure 12. Scheme of the bioprinting process combining extrusion and inkject modules. The process starts with the layer-by-layer deposition of polycaprolactone together with gelatin (sacrificial material) to generate the transwell system. Then, collagen I and human fibroblasts are extruded to form the dermis. After gelation, human keratinocytes are deposited on top of the gel using the inkjet module. The bilayered skin substitute is submerged in growth media at $37^{\circ} \mathrm{C}$ to reach cell confluency and remove the sacrificial material. Finally, epidermal differentiation is induced at the liquid-air interface in the presence of differentiation medium [108].

prints skin cells suspended in hydrogel precursors directly onto an injured area with a posterior crosslinking of the bioinks to replicate the layered 3D skin structure. Using this technique, Binder in his doctoral thesis, developed in house a software and bioprinting device composed of a cartridge delivery system containing a series of inkjet nozzles and a laser scanning system, both mounted on a portable XYZ plotting system [132-134]. The data obtained from the laser was used to reconstruct a 3D model of the wound, which was subsequently employed to determine the area and the 3D shape of the wound. Afterwards, the printheads filled the wound site with droplets of bioink containing fibroblasts, fibrinogen and collagen I, and simultaneously a spraying nozzle added the thrombin necessary to react for $15 \mathrm{~min}$ to crosslink fibrinogen into a fibrin hydrogel, and finally a layer of keratinocytes was printed. Human skin was printed following this method on the back of wounded nude mice, showing a significantly reduced time to wound closure when compared with untreated and fibrin/collagen controls. Printed skin closed the wound in 3 weeks compared with 5 weeks for controls. In a similar scenario, autologous and allogeneic skin fibroblasts and keratinocytes from porcine skin were printed directly into full thickness excisional wounds on the back of pig models. As the authors conclude: "wounds repaired with autologous fibroblasts and keratinocytes demonstrated increased epithelialization over all other treatments, although no statistically significant differences in wound size or contracture were detected." The same research group used a similar procedure and bioprinting technique to print amniotic fluid-derived stem cells and bone marrow-derived mesenchymal stem cells onto full-thickness skin wounds in mice [135]. The closure, re-epithelialization and neovascularization of wounds treated with these cells were significantly better than those of wounds treated only with the fibrin-collagen hydrogel. This technology is very innovative and promising but still immature. In particular, it needs to be clearly defined in which situations it is more appropriate to treat clinically relevant wounds, which are more complex than those produced in animal models as compared with the simpler ex vivo bioprinted skin. Clearly more experiments are necessary. 


\section{Conclusion \& future perspective}

Three-dimensional bioprinting of human tissues is leaving behind the initial stage of hype that many disruptive technologies experience as a result of high expectations created because of their great innovative potential; it is now entering into a more mature stage where difficulties are being identified and successes are progressively appearing. This is particularly true in the case of skin where, through the use of different printing methods and scaffolds, interfollicular skin has been printed with a structural and functional quality that is paving the way for clinical and industrial applications. Of course, there are many hurdles ahead, but in our opinion, bioprinted skin products will reach the market in the coming years, in particular for the testing of drugs, cosmetics and chemicals. If this hypothesis is correct, it would be necessary to evolve current bioprinters, bioprinting processes and bioinks design and production methods to be able to manufacture large amounts of differentiated 3D human skin testing units of reproducible quality that meet the standards and safety criteria required by the regulatory authorities, and at a much lower price than the present. That is, we must go from a technology used mainly for R\&D purposes to one designed for industrial production.

From a biological point of view, it is clear that printing interfollicular skin is merely a first step. Given its flexibility, precision and capacity to generate discrete bioink deposition, $3 \mathrm{D}$ printing is an ideal technology to begin progressively designing more complex skin equivalents that are more similar to normal skin. This could also lead to the generation of much better in vitro models of human cutaneous diseases or even to 'personalized' skin for the diagnosis or determination of the most effective treatment possible. This could even have applications in the field of cosmetics.

These more developed equivalents would include in a first step cells such as melanocytes, adipocytes and immune system cells, which are of great importance in skin physiology and pathology (UV response, inflammatory and autoimmune diseases, infections, etc.). However, in the long term, they should also include skin structures such as sweat glands and hair follicles and their associated sebaceous glands, since these structures have a decisive influence on skin and body physiology and on skin regeneration. Obviously, these structures will be difficult to achieve.

Cells play a crucial role in skin, but one should not forget the fundamental function of the dermal ECM. As described above (section 2), most of the experiments published so far relied basically on collagen I or fibrinogen/fibrin hydrogels with some use of noncutaneous molecules such gelatin, the latter being a sacrificial material. There is clearly room for the use of other types of materials; restricting ourselves to cutaneous extracellular ones, hyaluronic acid, elastin and collagen III should be taken into consideration. These materials form gradients in the dermis and therefore were difficult to handle before the advent of $3 \mathrm{D}$ bioprinting.

Finally, considering the clinical use of bioprinted skin, as commented in section 4, bioprinting methods, in particular those based on continuous extrusion, are able to assemble in a short time (a few hours) skin surfaces large enough to cover extensively burnt patients, which would probably be their most paradigmatic application. However, they alone do not significantly transcend the main obstacle affecting these patients' treatment, namely the length of time (3-4 weeks) required to generate enough autologous cells from the patient's own small biopsy. Moreover, printed interfollicular skin will likely not help overcome another major challenge: as demonstrated by the results obtained using hand-made equivalents, the take of the grafts depends critically on the infection status of the wound bed [57]. Biological improvements as those mentioned in the preceding paragraphs as well as additional components to be included in the printed skin are needed. Last but not least, bioprinted skin will surely be considered a medicine by the EMA and similarly so by the US FDA. Besides the potential tough requisite of performing clinical trials, this means costly production in clean rooms under good manufacturing practices conditions. Clearly, if bioprinted skin is to become widely used in the field of wound healing, in competition with other now standard, albeit more aggressive methods such as meshed autografts, shorter production times as well improved efficacy and lower prices compared with currently available hand-made skin equivalents have to be achieved. It is precisely 3D bioprinting that opens new opportunities for achieving these goals, but it is not going to be easy.

\section{Acknowledgements}

We thank the Spanish Fundación Ramón Areces for its continuous support. 
No writing assistance was utilized in the production of this manuscript.

\section{References}

1 Kanitakis J. Anatomy, histology and immunohistochemistry of normal human skin. Eur. J. Dermatol. 390-399; quiz 400-1 (2002).

2 Blanpain C, Fuchs E. Epidermal stem cells of the skin. Annu. Rev. Cell Dev. Biol. 22(1), 339-373 (2006).

3 Kolarsick PA. Anatomy and physiology of the skin. J. Dermatol. Nurse. Assoc. 3, 203-213 (2011).

4 A L Mescher. Junqueira's Basic Histology: Text and Atlas(13th Edition). McGraw-Hill Medical, USA (2013).

5 Proksch E. The skin: an indispensable barrier. Exp. Dermatol. 17(12), 1063-1072 (2008).

6 W Montagna. Skin Structure and Function (3rd Edition). Academic Press, Inc, Elsevier, New York and London (1974).

7 Chu DH. Overview of biology, development, and structure of skin. In: Fitzpatrick's Dermatology in General Medicine(7th Edition ). McGraw-Hill, NY, USA (2008).

8 James WD, Berger TG, Elston DM. Andrews' diseases of the skin. In: Clinical Dermatology 10th Edition. Elsevier Saunders, PA, USA (2006).

9 Murphy GF. Histology of the Skin (8th Edition). Lippincott Williams \& Wilkins, PA, USA (1997).

10 Coulombe PA, Kerns ML, Fuchs E. Epidermolysis bullosa simplex: a paradigm for disorders of tissue fragility. J. Clin. Invest. 119, 1784-1793, (2009).

11 Gache Y, Baldeschi C, Del Rio M et al. Construction of skin equivalents for gene therapy of recessive dystrophic epidermolysis bullosa. Hum. Gene. Ther. 15, 921-933 (2004)

12 Juhlin L. Hyaluronan in skin. J. Intern. Med. 242, 61-66 (1997).

13 Papakonstantinou E, Roth M, Karakiulakis G. Hyaluronic acid: a key molecule in skin aging. Dermatoendocrinol 4(3), 253-258 (2012).

14 Guo S, DiPietro LA. Factors affecting wound healing. J. Dent. Res.doi:10.1177/0022034509359125 (2005) (Epub ahead of print).

15 Diegelmann RF, Evans MC. Wound healing: an overview of acute, fibrotic and delayed healing. Front. Biosci. 9, 283-289 (2004)

16 Groeber F, Holeiter M, Hampel M et al. Skin tissue engineering - in vivo and in vitro applications. Adv. Drug Deliv. Rev. 63, 352-366 (2011).

17 Papini R. Management of burn injuries of various depths. BMJ 329(7458), 158-160 (2004).

18 Vijayavenkataraman S, Lu WF, Fuh JY. 3D bioprinting of skin: a state-of-the-art review on modelling, materials, and processes. Biofabrication 8(3), 032001 (2016).

19 Blanpain C, Lowry WE, Geoghegan A, Polak L, Fuchs E. Self-renewal, multipotency and existence of two cell populations within and epitelial stem cell niche. Cell 118(5), 635-648 (2004).

20 Blanpain C, Fuchs E. Epidermal stem cells of the skin. Annu. Rev. Cell Dev. Biol. 22, 339-373 (2006).

21 Chua AW, Khoo YC, Tan BK, Tan KC, Foo CL, Chong SJ. Skin tissue engineering advances in severe burns: review and therapeutic applications. Burns Trauma 4, 3 (2016).

22 MacNeil S. Progress and opportunities for tissue-engineered skin. Nature 445(7130), 874-880 (2007).

23 Brohem CA, Cardeal LB, Tiago M et al. Artificial skin in perspective: concepts and applications. Pigment. Cell Melanoma Res. 24(1), 35-50 (2011).

24 Vig K, Chaudhari A, Tripathi S et al. Advances in skin regeneration using tissue engineering. Int. J. Mol. Sci.doi:10.3390/ijms18040789 (2017) (Epub ahead of print).

25 Mathes SH, Ruffner H, Graf-Hausner U. The use of skin models in drug development. Adv. Drug Deliv. Rev. 69-70, 81-102 (2014).

26 Abd E, Yousef SA, Pastore MN et al. Skin models for the testing of transdermal drugs. Clin. Pharmacol. 8, 163-176 (2016).

27 Flaten GE, Palac Z, Engesland A et al. In vitro skin models as a tool in optimization of drug formulation. Eur. J. Pharm. Sci. 75, 10-24 (2015).

28 Peck MD. Epidemiology of burns throughout the world. Part I: distribution and risk factors. Burns 37, 1087-1100 (2011).

29 Peck MD. Epidemiology of burn injuries globally. Available from www.uptodate.com/contents/epidemiologyof-burn-injuries-globally

30 MedMarket Diligence, LLC Worldwide Wound Management. Forecast to 2024: established and emerging products, technologies and markets in the Americas, Europe, Asia/Pacific and Rest of World. http://mediligence.com/rpt/rpt-s251.htm

31 Transparent Market Research. Report 2015, tissue engineered skin substitutes market (by type - acellular, cellular allogeneic, cellular autologous, and others; by application - burn injury, diabetic/vascular ulcer, and others) - global industry analysis, size, share, growth, trends, and forecast 2015-2023 http://transparencymarketresearch.com/tissue-engineered-skinsubstitute.html

32 American Burn Association. Burn incidence and treatment in the United States (2016). http://ameriburn.org/resources_factsheet.php

33 Andreassi A, Bilenchi R, Biagioli M, D’Aniello C. Classification and pathophysiology of skin grafts. Clin. Dermatol. 23, 332-337 (2005). 
Loss M, Wedler V, Künzi W et al. Artificial skin, split-thickness autograft and cultured autologous keratinocytes combined to treat a severe burn injury of 93\%. Burns 26, 644-652 (2002).

Sheridan R. Closure of the excised burn wound: autografts, semipermanent skin substitutes, and permanent skin substitutes. Clin. Plast. Surg. 36, 643-651 (2009).

Groeber F, Holeiter M, Hampel M et al. Skin tissue engineering - in vivo and in vitro applications. Adv. Drug Deliv. Rev. 63, 352-366 (2011). new skin substitutes. Stem Cells 26, 2713-2723 (2008).

Supp DM, Boyce ST. Engineered skin substitutes: practices and potentials. Clin. Dermatol. 23, 403-412 (2005).

5 Huber B, Link A, Linke K, Gehrke SA, Winnefeld M, Kluger PJ. Integration of mature adipocytes to build-up a functional three-layered full-skin equivalent. Tissue Eng. 22(8), 756-764 (2016).

Bellas E, Seiberg M, Garlick J, Kaplan DL. In vitro 3D full-thickness skin-equivalent tissue model using silk and collagen biomaterials. Macromol. Biosci. 12(12), 1627-1636 (2012)

47 Monfort A, Soriano-Navarro M, García-Verdugo JM, Izeta A. Production of human tissue-engineered skin trilayer on a plasma-based hypodermis. J. Tissue Eng. Regen. Med. 7(6), 479-490 (2013).

48 Chaudhari AA, Vig K, Baganizi DR et al. Future prospects for scaffolding methods and biomaterials in skin tissue engineering: a review. Int. J. Mol. Sci. 17(12), 1974 (2016).

49 Jeon K-H, Park D, Lee Y-C. Polymer-based hydrogel scaffolds for skin tissue engineering applications: a mini-review. J. Polym. Res. 24(7), 112 (2017).

50 Norouzi M, Boroujeni SM, Omidvarkordshouli $\mathrm{N}$ et al. Advances in skin regeneration: application of electrospun scaffolds. Adv. Healthcare Mat. 4(8), 1114-1133 (2015).

51 MacNeil S. Biomaterials for tissue engineering of skin. Materials Today 11(5), 26-35 (2005). Priya SG, Jungvid H, Kumar A. Skin tissue engineering for tissue repair and regeneration. Tissue Eng. Part B 14(1), 105-118 (2008).

54 Cen L, Liu W, Cui L et al. Collagen tissue engineering: development of novel biomaterials and applications. Pediatr. Res. 63(5), 492-496 (2008).

Geer DJ, Swartz DD, Andreadis ST. Fibrin promotes migration in a three dimensional in vitro model of wound regeneration. Tissue Eng. 8, 787-798 (2002).

57 Meana A, Iglesias J, Del Rio $\mathrm{M}$ et al. Large surface of cultured human epithelium obtained on a dermal matrix based on live fibroblast-containing fibrin gels. Burns 24, 621-630 (1998).

Llames SG, Del Rio M, Larcher F et al. Human plasma as a dermal scaffold for the generation of a completely autologous bioengineered skin. Transplantation 77, 350-355 (2004).

60 Boyce ST. Design principles for composition and performance of cultured skin substitutes. Burns 27, 523-533 (2001).

61 Shakespeare PG. The role of skin substitutes in the treatment of burn injuries. Clin. Dermatol. 23, 413-418 (2005).

62 Peng W, Unutmaz D, Ozbolat IT. Bioprinting towards physiologically relevant tissue models for pharmaceutics. Trends Biotechnol. 34(9), 722-732 (2016).

63 Holmes AM, Charlton A, Derby B et al. Rising to the challenge: applying biofabrication approaches for better drug and chemical product development. Biofabrication 9(3), 033001 (2017).

64 Dababneh AB, Ozbolat IT. Bioprinting technology: a current state-of-the-art review. ASME. J. Manuf. Sci. Eng. 136(6) MANU-14-1211 (2014). doi:10.1115/1.4028512

65 Guillemot F, Mironov V, Nakamura M. Bioprinting is coming of age: report from the International Conference on Bioprinting and Biofabrication in Bordeaux (3B'09). Biofabrication 2(1), 010201 (2010).

66 Visconti RP, Kasyanov V, Gentile C, Zhang J et al. Towards organ printing: engineering an intra-organ branched vascular tree. Expert Opin. Biol. Ther. 10(3), 409-420 (2010). 
67 Mironov V, Kasyanov V, Drake C et al. Organ printing: promises and challenges. Regen. Med. 3(1), 93-103 (2007).

68 Derby B. Printing and prototyping of tissues and scaffolds. Science 338, 921-926 (2012).

69 Murphy SV, Atala A. 3D bioprinting of tissues and organs. Nat. Biotechnol. 32, 773-785 (2014).

70 Arslan-Yildiz A, El Assal R, Chen P, Guven S, Inci F, Demirci U. Towards artificial tissue models: past, present, and future of 3D bioprinting. Biofabrication 8(1), 014103 (2016).

71 Cui H, Nowicki MH, Fisher JP, Zhang LG, Zhang LG. 3D bioprinting for organ regeneration. Adv. Healthcare Mater. 6, 1601118 (2017).

72 Mironov V, Kasyanov V, Markwald RR. Organ printing: from bioprinter to organ biofabrication line. Curr. Opin. Biotech. 22(5), 667-673 (2011).

73 Shafiee A, Atala A. Printing technologies for medical applications. Trends Mol. Med. 22, 254-265 (2016).

74 Michael Shanler, Pete Basiliere, Hype Cycle for 3D Printing. ID: G00314553 (2017) www.gartner.com/doc/3759564/hype-cycle-d-printing-

75 Li M, Tian X, Schreyer DJ, Chen X. Effect of needle geometry on flow rate and cell damage in the dispensing-based biofabrication process. Biotechnol. Prog. 27(6), 1777-1784 (2011).

76 Hölzl K, Lin S, Tytgat L, van Vlierberghe S, Gu L, Ovsianikov A. Bioink properties before, during and after 3D bioprinting. Biofabrication 8, 032002 (2016).

77 Donderwinkel I, van Hest JCM, Cameron NR. Bio-inks for 3D bioprinting: recent advances and future prospects. Polym. Chem. 8, 4451-4471 (2017).

78 Ji S, Guvendiren M. Recent advances in bioink design for 3D bioprinting of tissues and organs. Front. Bioeng. Biotechnol. 5, 23 (2017).

79 Guvendiren M, Molde J, Soares RMD, Kohn J. Designing biomaterials for 3D printing. ACS Biomater. Sci. Eng. 2(10), 1679-1693 (2016).

80 Blaeser A, Duarte Campos DF, Puster U, Richtering W, Stevens MM, Fischer H. Controlling shear stress in 3D bioprinting is a key factor to balance printing resolution and stem cell integrity. Adv. Healthcare Mater. 5(3), 326-333 (2016).

81 Aguado BA, Mulyasasmita W, Su J, Lampe KJ, Heilshorn SC. Improving viability of stem cells during syringe needle flow through the design of hydrogel cell carriers. Tissue Eng. Part A 18(7-8), 806-815 (2012).

82 Chang R, Nam J, Sun W. Effects of dispensing pressure and nozzle diameter on cell survival from solid freeform fabrication-based direct cell writing. Tissue Eng. A14, 41-48 (2008)

83 Watt FM, Jordan PW, O’Neill CH. Cell shape controls terminal differentiation of human epidermal keratinocytes. Proc. Natl Acad. Sci. USA 85(15), 5576-5580 (1988).

84 Malda J, Visser J, Melchels FP et al. 25th Anniversary article: engineering hydrogels for biofabrication. Adv. Mater. 25, 5011-5028 (2013).

85 Yong HE. Research on the printability of hydrogels in 3D bioprinting. Sci. Rep. 6, 29977 (2016).

86 Jungst T, Smolan W, Schacht K, Scheibel T, Groll J. Strategies and molecular design criteria for 3D printable hydrogels. Chem. Rev. 2016, 116(3), 1496-1539 (2016).

87 Hinton T, Jallerat Q, Palchesko RN et al. Three-dimensional printing of complex biological structures by freeform reversible embedding of suspended hydrogels. Sci. Adv. 1(9), 1500758 (2015).

88 Kang HW, Lee SJ, Ko IK, Kengla C, Yoo JJ, Atala A. A 3D bioprinting system to produce human-scale tissue constructs with structural integrity. Nat. Biotechnol. 34(3), 312-319 (2016).

89 Zhu W, Ma X, Gou M, Mei D, Zhang K, Chen S. 3D printing of funtional biomaterials for tissue engineering. CCurr. Opin. Biotechnol. 40, 103-112 (2016).

90 Chia HN, Wu BM. Recent advances in 3D printing of biomaterials. J. Biol. Eng. doi:10.1186/s13036-015-0001-4 (2015) (Epub ahead of print).

91 Zhu YK, Umino T, Liu XD et al. Contraction of fibroblast-containing collagen gels: initial collagen concentration regulates the degree of contraction and cell survival. In Vitro Cell Dev. Biol. Anim. 37(1), 10-16 (2001).

92 Grinnell F. Fibroblast-collagen-matrix contraction: growth-factor signalling and mechanical loading. Trends Cell Biol. 10(9), 362-365 (2000).

93 Pourchet LJ, Thepot A, Albouy M et al. Human skin 3D bioprinting using scaffold-free approach. Adv. Healthcare Mater. 6(4), 1601101 (2017).

94 Ozbolat IT, Moncal KK, Gudapati H. Evaluation of bioprinter technologies. Addit. Manuf. 13, 179-200 (2017).

95 Pereira RF, Sousa A, Barrias CC, Bayat A, Granja PL, Bartolo PJ. Advances in bioprinted cell-laden hydrogels for skin tissue engineering. Biomanuf. Rev. 2(1) (2017).

96 Mironov V, Boland T, Trusk T, Forgacs G, Markwald RR. Organ printing: computer-aided jet-based 3D tissue engineering. Trends Biotechnol. 21(4), 157-161 (2003). 
97 Ozbolat IT, Hospodiuk M. Current advances and future perspectives in extrusion-based bioprinting. Biomaterials 76, 321-343 321e343 (2016).

98 Boland T, Mironov V, Gutowska A, Roth EA, Markwald RR. Cell and organ printing 2: fusion of cell aggregates in three-dimensional gels. Anat. Rec. A Discov. Mol. Cell. Evol. Biol. 272(2), 497-502 (2003).

99 Mironov V, Visconti RP, Kasyanov V, Forgacs G, Drake CJ, Markwald RR. Organ printing: tissue spheroids as building blocks. Biomaterials 30, 2164-2174 (2009)

100 Jakab K, Norotte C, Marga F, Murphy K, Vunjak G, Forgacs G. Tissue engineering by self-assembly and bio-printing of living cells. Biofabrication 2, 22001 (2010).

101 Mehesz AN, Brown J, Hajdu Z et al. Scalable robotic biofabrication of tissue spheroids. Biofabrication 3, 25002 (2011).

102 Chung JHY, Naficy S, Yue Z et al. Bio-ink properties and printability for extrusion printing living cells. J. Biomater. Sci. Polym. Ed. 1(7), 763-773 (2013).

103 Khalil S, Sun W. Bioprinting endothelial cells with alginate for 3D tissue constructs. J. Biomech. Eng. 131(11) 111002 (2009).

104 Murphy SV, Skardal A, Atala A. Evaluation of hydrogels for bio-printing applications. J. Biomed. Mater. Res A 101(1), 272-284 (2013).

105 Levato R, Visser J, Planell J, Engel E, Malda J, Mateos-Timoneda M. Biofabrication of tissue constructs by 3D bioprinting of cell-laden microcarriers. Biofabrication 6(3), 035020 (2014).

106 Pati F, Jang J, Ha D-H et al. Printing three-dimensional tissue analogues with decellularized extracellular matrix bioink. Nat. Commun. 5, 3935 (2014).

107 Dababneh AB, Ozbolat IT. Bioprinting technology: a current state-of-theart review. J. Manuf. Sci. Eng. 136, 061016 (2014).

108 Kim BS, Lee JS, Gao G, Cho DW. Direct 3D cell-printing of human skin with functional transwell system. Biofabrication 9(2), 025034 (2017).

109 Cubo N, Garcia M, Del Cañizo JF, Velasco D, Jorcano JL. 3D bioprinting of functional human skin: production and in vivo analysis. Biofabrication 9(1), 015006 (2017).

110 Le HP. Progress and trends in ink-jet printing technology. J. Imaging Sci. Technol. 42(1), 49-62 (1998).

111 Gudapati H, Dey M, Ozbolat I. A comprehensive review on droplet-based bioprinting: past, present and future. Biomaterials 102, 20-42 (2016).

112 Wijshoff HH. The dynamics of the piezo inkjet printhead operation. Phys. Rep. 491(4-5), 77-177 (2010).

113 Cui X, Boland T. Human microvasculature fabrication using thermal inkjet printing technology. Biomaterials 30(31), 6221-6227 (2009).

114 Nishiyama Y, Nakamura M, Henmi C et al. Development of a three-dimensional bioprinter: construction of cell supporting structures using hydrogel and state-of-the-art inkjet technology. J. Biomech. Eng. 131(3), 035001 (2009).

115 Lee V, Singh G, Trasatti JP et al. Design and fabrication of human skin by threedimensional bioprinting. Tissue Eng. Part C 20, 473-484 (2014).

116 Lee W, Debasitis JC, Lee VK et al. Multi-layered culture of human skin fibroblasts and keratinocytes through three-dimensional freeform fabrication. Biomaterials 30, 1587-1595 (2009).

117 Koch L, Gruene M, Unger C, Chichkov B. Laser assisted cell printing. Curr. Pharm. Biotechnol. 14(1), 91-97 (2013).

118 Barron JA, Ringeisen BR, Kim H, Spargo BJ, Chrisey DB. Application of laser printing to mammalian cells. Thin Solid Films 453-454, 383-387 (2004).

119 Schiele NR, Corr DT, Huang Y, Raof NA, Xie Y, Chrisey DB. Laser-based direct-write techniques for cell printing. Biofabrication 2(3), 032001 (2010).

120 Riggs BC, Dias AD, Schiele NR, Cristescu R. Matrix-assisted pulsed laser methods for biofabrication. MRS Bull. 36(12), 1043-1050 (2011).

121 Guillemot F, Souquet A, Catros S et al. High-throughput laser-printing of cells and biomaterials for tissue engineering. Acta Biomater 6(7), 2494-2500 (2010).

122 Guillotin B, Souquet A, Catros S et al. Laser-assisted bio-printing of engineered tissue with high density and microscale organization. Biomaterials 31(28), 7250-7256 (2010).

123 Michael S, Sorg H, Peck CT et al. Tissue engineered skin substitutes created by laser assisted bioprinting form skin-like structures in the dorsal skin fold chamber in mice. PLoS One 8(3), 57741 (2013).

124 Ng WL, Wang S, Yeong WY, Naing MW. Skin bioprinting: impeding reality or fantasy?. Trends Biotechnol. 34(9), 689-699 (2016).

125 Michael AP, Sandra JS. Immortalized human keratinocyte cell line. Inventor Lynn Allen-Hoffmann. European patent aplication 7-13 (1998) EP1693066A3 EP Application.

126 Koch L, Deiwick A, Schlie S et al. Skin tissue generation by laser cell printing. Biotechnol. Bioeng. MedSkin Solutions, 109, 1855-1863 (2012). 
127 Dr. Suwelack AG, MedSkin Solutions. www.medskin-suwelack.com/en/matriderm.html

128 Min D, Lee W, Bae IH, Lee TR, Croce P, Yoo SS. Bioprinting of biomimetic skin containing melanocytes. Exp. Dermatol. 00, 1-7 (2017).

129 Yanez M, Rincon J, Dones A, De Maria C, Gonzales R, Boland T. In vivo assesment of printed microvasculature in a bilayer skin graft to treat full-thickness wounds. Tissue Eng. Part A 21(1-2), 224-233 (2015).

130 Ng WL, Qi JTZ, Yeong WY, Naing MW. Proof-of-concept: 3D bioprinting of pigmented human skin constructs. Biofabrication 10(2), 025005 (2018).

131 Wang MY, He JK, Liu YX et al. The trend towards in vivo bioprinting. Int. J. Bioprinting 1(1): 15-26 (2015).

132 Binder KW. In situ bioprinting of the skin (doctoral dissertation). (2011). https://wakespace.lib.wfu.edu

133 Yoo JJ, Atala A, Binder KW et al. Delivery system. US patent application 20110172611. (2011). https://patents.google.com/patent/US20110172611

134 Binder KW, Zhao W, Aboushwareb T, Dice D, Atala A, Yoo JJ. In situ bioprinting of the skin for burns. J. Am. Coll. Surg. 211, S76-S76 (2010).

135 Skardal A, Mack D, Kapetanovic E et al. Bioprinted amniotic fluid-derived stem cells accelerate healing of large skin wounds. Stem Cells Transl. Med. 1, 792-802 (2012). 